\title{
Data-Driven Artificial Intelligence in Education: A Comprehensive Review
}

\author{
Kashif Ahmad • Waleed Iqbal • Ammar \\ El-Hassan • Junaid Qadir • Driss Benhaddou • \\ Moussa Ayyash • Ala Al-Fuqaha
}

Received: date / Accepted: date

\begin{abstract}
As Education constitutes an essential development standard for individuals and societies, researchers have been exploring the use of Artificial Intelligence (AI) in this domain and have embedded the technology within it through a myriad of applications. In order to provide a detailed overview of the efforts, this article pays particular attention to these developments by highlighting key application areas of data-driven AI in Education; it also analyzes existing tools, research trends, as well as limitations of the role data-driven AI can play in Education. In particular, the article reviews various applications of AI in Education including student grading and assessments, student retention and drop-out predictions, sentiment analysis, intelligent tutoring, classroom monitoring and recommender systems. The article also provides detailed bibliometric analysis to highlight the salient research trends in AI in Education over seven years (2014-2020) and further provides detailed description of the tools and platforms developed as the outcome of research and development
\end{abstract}

Division of Information and Computing Technology, College of Science and Engineering, Hamad Bin Khalifa University (HBKU)

Education City, Doha, Qatar

E-mail: kahmad@hbku.edu.qa

W. Iqbal

Queen Mary University London, United Kingdom

A. El-Hassan

Princess Sumaya University for Technology, Amman, Jordan

J. Qadir

Information Technology University (ITU), Lahore, Pakistan

D. Benhaddou

University of Houston, USA

M. Ayyash

Chicago State University, Chicago, USA

A. Al-Fuqaha

Hamad Bin Khalifa University (HBKU), Doha, Qatar 
efforts in AI and Education. For the bibliometric analysis, articles from several top venues are analyzed to explore research trends in the domain. The analysis shows sufficient contribution in the domain from different parts of the world with a clear lead for the United States. Moreover, students' grading and evaluation have been observed as the most widely explored application. Despite the significant success, we observed several aspects of education where AI alone can not contribute much. We believe such detailed analysis is expected to provide a baseline for future research in the domain.

Keywords AI - Education · E-learning - Personalized Learning · ML · Intelligent Tutoring Systems (ITS) · Educational Data Mining (EDM)

\section{Introduction}

In the modern world, Artificial Intelligence (AI) is revolutionizing the way humans live their life. Similar to other domains, the field of education is also going through a paradigm shift through the use of AI, which can be used to unleash insights about understanding how students learn, how to personalize the learning experience of students, how to get more information to help in the decision-making process, how to model the complex interaction between student learning, the knowledge domain, and the tools that enable students to interact with the domain. AI can be useful in addressing education-related challenges that are rooted in both the inadequacy of the traditional way of teaching the current generation and the complexity of the educational system itself. Over the past decade, the role of AI in learning has been on the radar of education institutions, government agencies, funding agencies, and industry [1]. It is expected to grow by more than $47 \%$ from 2018 to 2022 in the US Education Sector based on AI Market [2].

We use the term AI broadly as an umbrella term that subsumes methods, algorithms, and systems that learn from data (data science, statistical learning, machine learning, deep learning) or aim to create machine intelligence that can perform tasks such as perception, reasoning, inference (such as expert systems, probabilistic graphical models, Bayesian networks). These terms are largely used in current convention synonymously [3], and our use of the term AI will ease exposition and reduce clutter. We make the distinction between AI and other subsumed techniques where it is important. It is worth noting though that there are various types of AI techniques, and not all of them are connectionist (i.e., based on neural networks and deep learning) [4].

The AI techniques in education can be broadly divided into two different categories, namely (i) representational/knowledge-based AI, and (ii) datadriven AI [5]. The knowledge-based AI algorithms aim to employ human experts knowledge in decision making, such as rule-based systems. The majority of the efforts in the previous decade were based on knowledge-based AI [6]. However, recently the trend shifted towards data-driven techniques. In this paper, we focus predominantly on data-driven AI techniques in education and 
review the recent efforts made in the domain with a particular focus on applications and tools.

There are three main roles for AI in education including assisting (i) individual students, (ii) the whole class, and (iii) the whole cohorts of students [7]. At the individual level, the focus is more on adapting teaching methods and approaches to a particular learner's needs. The systems developed as a result of such efforts are termed as "Intelligent Tutoring Systems (ITS)", which are found as much effective as human tutors [8]. On the other hand, at the classlevel, AI aims to help teachers in managing a whole class instead of individual learners [9]. Some key applications of AI in the classroom include tutoring, grading, and Virtual Reality (VR) based learning to improve the teaching and learning experience in a classroom via an effective teacher and AI collaboration [10]. At the cohort-level, AI aims to analyze learners' interaction with the systems and tune the learning system based on the failure and success of learners' interaction with the system. Some key applications at the cohortlevel include identification of learners at the risk, learners' interests, behavior, performance, and dropout prediction.

Different research communities have taken different approaches to the use of data-driven methods for addressing educational problems at different levels. For instance, the data mining research community addresses educational research problems using a big data approach while AI communities address research problems focusing on algorithms and methodologies as part of their efforts towards the development of interactive and adaptive learning environments. Although these fields are overlapping, these communities tend to develop distinct research areas as they have had different research histories. The Knowledge Discovery and Data Mining (KDD) research community aim to discover patterns and extract knowledge through data mining techniques. The Educational Data Mining (EDM) community attracts inter-disciplinary scientists from computer science, education, psychometrics, and other fields to analyze data acquired from the educational environment and apply data mining techniques to solve educational challenges [11-13]. On the other hand, the Society for Learning Analytics Research (SoLAR) community is an "interdisciplinary network of leading international researchers who are exploring the role and impact of analytics on teaching, learning, training and development" $[14,15]$. It is to be noted that AI in education is not limited to EDM, learning analytics, and machine learning. In fact, EDM, SOLAR, and learning analytics grew out of AI in education, and many other research activities are being developed by different research groups around the world to explore how AI can be utilized to solve educational problems.

\subsection{Scope of the Survey}

The paper revolves around the key applications of data-driven AI techniques in education. The paper describes the most commonly used data-driven AI techniques in different applications of education. It also describes the tools and 
platforms developed in the market as outcomes of the research work achieved in different applications including (i) student's grading and evaluations, (ii) students' retention and drops out prediction, (iii) personalized learning (iv) students' performance analysis and prediction, (v) sentiment analysis, (vi) recommendation systems in education, (vii) classrooms' monitoring and visual analysis, and (viii) intelligent tutoring. We also analyze research trends in AI applications in education by providing a detailed bibliometric analysis of the domain. The paper also advises on the current limitations, pitfalls, and future directions of research in the domain, and how it can fill the current gaps.

\subsection{Related Surveys}

In the literature, several interesting articles analyzing different aspects of AI applications in education have been proposed. There are also some surveys targeting specific application areas of AI in education [16]. To the best of our knowledge, there is no recent detailed survey covering the domain from different perspectives. In previous works, Romero et al. [12] provides a general review of existing literature to analyze how EDM and LA has been applied over educational data. Romero et al. [17] surveyed the educational data mining literature for a decade (i.e., 1995 to 2005). Baker et al. [18] reported a detailed survey of data mining techniques used in the education sector. More recently, Fischer et al. [19] surveyed the existing data mining techniques in education with a particular focus on highlighting challenges in mining big data. Mduma et al. [20] focused on students' retention and dropout prediction techniques. Almasri et al. [21] provide a detailed survey of Intelligent Tutoring Systems (ITS), another attractive application of AI in education, proposed from 2000 to 2018. Tahiru [22] provides a systematic review of AI in certain applications of AI in education, such as ITS, automation of administrative tasks, and developing smart content. Al-Emran et al. [23] surveyed the Internet of Things (IoT)-based educational solutions. In contrast to the existing surveys, this paper provides a broader picture of the domain by covering most of the key application areas of AI in education, such as student's grading and evaluations, students' retention and drop out prediction, students' performance, e-learning, sentiment analysis, education data mining, education quality support recommendation systems, classrooms' monitoring and ITS. The paper also highlights the key market players, tools, and platforms along with key challenges, potential market opportunities, future research directions, and pitfalls of AI in education. More importantly, we analyze the trends of the research in the domain from a different perspective by providing a detailed bibliometric analysis of the domain. Table 1 provides summary of existing surveys on the topic.

\subsection{Contributions}

The main contributions of the work are summarized as follows: 
Table 1: Comparison of our paper against existing surveys.

\begin{tabular}{|c|c|c|c|c|}
\hline Survey & Application Domains & $\begin{array}{l}\text { Tools \& } \\
\text { Platforms }\end{array}$ & $\begin{array}{l}\text { Bibliometric } \\
\text { Analysis }\end{array}$ & $\begin{array}{l}\text { Pitfalls } \\
\text { of AI }\end{array}$ \\
\hline [11] & $\begin{array}{l}\text { Covered } 2 \text { applications. (i) Students' Performance } \\
\text { Prediction and (ii) Recommendation Systems }\end{array}$ & $\checkmark$ & Yes (2005-2010) & $\mathrm{x}$ \\
\hline [18] & Not Covered. & $\mathrm{X}$ & Yes $(2000-2008)$ & $\mathrm{X}$ \\
\hline [19] & $\begin{array}{l}\text { Covered } 4 \text { applications. (i) Students Grading } \\
\text { and Evaluation, (ii) Students' Retention and } \\
\text { Dropout, (iii) Sentiment Analysis in Education } \\
\text { and (iv) Recommendation Systems in Education }\end{array}$ & $\mathrm{x}$ & $\mathrm{x}$ & $\mathrm{x}$ \\
\hline$[20]$ & $\begin{array}{l}\text { Covered } 1 \text { application. (i) Students' Retention and } \\
\text { Dropout }\end{array}$ & $\mathrm{X}$ & $\mathrm{X}$ & $\mathrm{X}$ \\
\hline [21] & $\begin{array}{l}\text { Covered } 2 \text { applications. (i) Students' Performance } \\
\text { Prediction and (ii) Intelligent Tutoring Systems }\end{array}$ & $\checkmark$ & $\mathrm{x}$ & $\mathrm{x}$ \\
\hline [24] & $\begin{array}{l}\text { Covered 10 applications. (i) Profiling and pre- } \\
\text { diction, (ii) Admission decisions and course } \\
\text { scheduling, (iii) Drop-out and retention, (iv) } \\
\text { Student models and academic achievement, (v) } \\
\text { ITS, (vi) Curating learning materials based on } \\
\text { student needs, (vii) Facilitating collaboration } \\
\text { between learners, (Viii) Assessment and evalu- } \\
\text { ation, (ix) Automated grading, and (x) Evalua- } \\
\text { tion of teaching }\end{array}$ & $\mathrm{X}$ & $\mathrm{X}$ & $\mathrm{X}$ \\
\hline $\begin{array}{l}\text { This } \\
\text { Work }\end{array}$ & $\begin{array}{l}\text { Covered } 9 \text { applications. (i) Students' Grading } \\
\text { and Evaluation, (ii) Students' Retention and } \\
\text { Dropout, (iii) Personalized Learning, (iv) Stu- } \\
\text { dents' Performance Prediction, (v) Sentiment } \\
\text { Analysis in Education, (vi) Recommendation } \\
\text { Systems in Education, (vii) Classroom Monitor- } \\
\text { ing \& Visual Analysis and (viii) Intelligent Tu- } \\
\text { toring Systems }\end{array}$ & $\checkmark$ & Yes (2014-2020) & $\checkmark$ \\
\hline
\end{tabular}

- The paper provides a detailed overview of the existing literature in nine different application domains in which AI is deployed for education.

- The paper also describes and highlights recent papers on the most commonly used learning strategies adopted in the literature over the years for these applications.

- The paper also explores and identifies the future scope and market opportunities for AI researchers and developers in the education sector.

- The paper analyzes the publication trends of the research literature taking into account a total of 3246 papers published in various top subject venues through a detailed bibliometric analysis in terms of research productivity by authors, institution, and country, and knowledge flow across various research venues.

- The paper also identifies the research and development companies and corporations working in the domain along with the tools and platforms available for both educational institutes and researchers.

- The paper also highlights the limitations, pitfalls, and open research challenges in using data-driven AI in education.

The rest of the paper is organized as follows. Section 2 describes some key application domains of AI in education and different tools developed as part of the efforts. Section 3 details some key AI techniques employed in different applications of education. Section 4 provides a comprehensive bibliometric analysis of the existing literature. Section 5 provides basic insights of the domain based on our analysis of the existing literature, and lists the key limitations and pitfalls of AI in education along with some potential directions of future research and open issues in the domain. Finally, Section 6 concludes the paper. 


\section{AI Applications in Education}

As part of the efforts in the domain, several interesting AI-based tools and applications have been introduced to facilitate educators in different ways. Moreover, several international standards, such as Caliper, xAPI, NGDLE (Next Generation Digital Learning Environment), are proposed to provide guidelines for data collection, storage, and analytics in for these applications [25]. In the next sub-sections, we provide an overview of existing literature in these applications as well as the tools and platforms developed as part of these efforts.

\subsection{Students' Grading and Evaluation}

In the literature, several AI techniques have been used to develop accurate models for the prediction of student behavior and in-class performance. For instance, Livers et al. [26] evaluated two wrapper methods for semi-supervised learning algorithms designed to predict the performance of students in their final examination. Their experimental results indicated a higher classification accuracy for the semi-supervised methods employing the unlabelled data along with the fewer labeled samples in training the models.

Although predicting the performance of students is a very important aspect of modern education supported by AI technologies especially as this helps education administration to put in place measures to preempt and prevent student dropouts before the end of the semester and mark the students who require special support. The performance aspects of students learning that need to be assessed are not always related to grading and marks but also include, very importantly, students learning difficulties. To analyze the learning difficulties faced by students, Hussain et al. [27] conduct a study to predict difficulties encountered by students in a digital design course. To this aim, the authors analyzed data logs from a Technology-Enhanced Learning environment (TEL) system using several AI algorithms including Artificial Neural Networks (ANN), Support Vector Machines (SVM), Logistic Regression, Decision Trees as well as naïve Bayes models. The test rig monitors students click behavior while solving digital design exercises of varying difficulty and collects students' total number of activities, average time, average idle time, the average number of keystrokes, and total related activity for each exercise; the output/predicted variable is the student grade in each session. AI models were then trained on old sessions to predict student performance in new sessions. Based on the experimental results, the authors conclude that the proposed ANNs and SVMs based students' performance prediction methods could be easily integrated into the TEL system allowing the teachers to evaluate and report improved student's performance during the subsequent session.

Data-driven AI methods for student performance prediction have also been applied by Masci et al. [28], who analyze test scores of students' PISA 2015 in nine countries to correlate students and schools' characteristics with stu- 
dents' performances. The authors also model interactions between school-level factors affecting results. To estimate school value-added factors, they apply flexible tree-based methods in combination with multilevel regression trees and subsequently use regression trees and boosting models to map the estimated school value-added factors to school-level variables. They conclude that although characteristics of students and schools are strongly linked to student achievements, the results vary from one county to another quite significantly which means it is essential to take the structural differences between international education systems into consideration whenever studies are conducted and conclusions are made.

As part of such efforts, several automatic grading tools are developed to analyze, assess, and score students' assignments and tests. A summary of some of the existing AI-based grading and evaluation tools and platforms has been provided in Table 2 .

Table 2: Summary of tools/platforms for students' grading and evaluation.

\begin{tabular}{|c|c|c|c|}
\hline Tool/platform & Provider & Domain & Key Features \\
\hline WriteToLearn [29] & Pearson & $\begin{array}{l}\text { Generic (text } \\
\text { only) }\end{array}$ & $\begin{array}{l}\text { - Automated assessments, scoring system, and re- } \\
\text { porting to teachers } \\
\text { - An immediate feedback to students to better } \\
\text { practice } \\
\text { - Focuses on summary and essay writing } \\
\text { - Teacher as well as student reporting capabilities }\end{array}$ \\
\hline $\begin{array}{l}\text { Quantum Adaptive } \\
\text { Learning and As- } \\
\text { sessment [30] }\end{array}$ & Quantum & Generic & $\begin{array}{l}\text { - Provides a question answer facilities where stu- } \\
\text { dents can put their inquiry } \\
\text { - Acts as a cognitive coach observing the thinking } \\
\text { and questioning expertise of the students }\end{array}$ \\
\hline $\begin{array}{l}\text { Azure } \text { Cloud } \text { AI } \\
\text { Tools for Educa- } \\
\text { tion [31] }\end{array}$ & Microsoft & $\begin{array}{l}\text { Computer } \\
\text { Science }\end{array}$ & $\begin{array}{l}\text { - Facilitates all stakeholders in the education sec- } \\
\text { tor including students, teachers and administra- } \\
\text { tion } \\
\text { - Provide deep analytical insights into student } \\
\text { performances and then be visually displayed us- } \\
\text { ing Microsoft PowerB dashboards } \\
\text { - Coding courses and tutorials } \\
\text { - Helps students to pursue careers in technology } \\
\text { or other fields }\end{array}$ \\
\hline Hubert.ai [32] & Hubert & Generic & $\begin{array}{l}\text { - Makes use of chat-bot technology and AI to en- } \\
\text { gage and extract actionable insights from stu- } \\
\text { dents' personalized conversations } \\
\text { - Provides an attractive user interface } \\
\text { - Able to extract qualitative insights from its per- } \\
\text { sonalized conversations with students } \\
\text { - Posses the ability of intelligent follow-up ques- } \\
\text { tions }\end{array}$ \\
\hline Lightside [33] & $\begin{array}{l}\text { Turnitin } \\
\text { and } \\
\text { Carnegie } \\
\text { Mellon }\end{array}$ & Text only & $\begin{array}{l}\text { - Evaluates of students' writing } \\
\text { - Provides feedback on the use of language, focus } \\
\text { of the document, organization and evidence } \\
\text { - Specially customized for students in grades six } \\
\text { through } 12\end{array}$ \\
\hline Proctorio [34] & Proctorio & Generic & $\begin{array}{l}\text { - Fully automated exam proctoring without } \\
\text { scheduling 24 hours a day, } 7 \text { days a week } \\
\text { - Supports automatic ID verification } \\
\text { - Provides admin dashboard and aggregates exam } \\
\text { data } \\
\text { - } \begin{array}{ll}\text { Ensures content protection } \\
\text { copy/print/download restrictions }\end{array} \\
\end{array}$ \\
\hline Gradescope [35] & Turnitin & $\begin{array}{l}\text { Multiple sub- } \\
\text { jects }\end{array}$ & $\begin{array}{l}\text { - Supports grading of paper-based, digital, and } \\
\text { code assignments } \\
\text { - Also provides insights on students' perfor- } \\
\text { mances } \\
\text { - Covers multiple subjects }\end{array}$ \\
\hline Respondus [36] & Respondus & Generic & $\begin{array}{l}\text { - Supports both K-12 and higher education } \\
\text { - Uses LockDown Browser to prevent cheating } \\
\text { - Creates exams questions }\end{array}$ \\
\hline
\end{tabular}




\subsection{Students' Retention and Dropout Prediction}

Student retention and dropout is a universal factor affecting both online and offline learning platforms. For instance, within Baccalaureate programs in the US, billions are lost each year due to dropout rates reaching $30 \%$ or more amongst first-year students because of insufficient quantitative analysis of causes and remedies of student attrition. As an initial effort, Aulck et al. [37] have modeled student dropout based on a dataset of 32500 demographics and transcript records at a large public institute. They conclude that early potential dropouts can be detected even with single term transcripts thus opening the door for AI applications to predict and prevent some of the causes of dropouts. The adverse effects of dropouts are manifested even more clearly in massive open online course (MOOC) environments due to the higher rates of dropout with typical enrollments of 10000 entrants and dropout rates reaching $90 \%$ [38].

In the literature, AI modeling techniques have been applied to predict dropout rates to calculate dropout probability as well as identify the ambient, demographic and individual factors related to learning activities such that education administrators can design effective intervention and prevention remedies. For example, Solis et al. [39] analyzed the accuracy of various AI algorithms for the prediction of student retention rates at university levels. They found that the Random Forest (RF) algorithm is an optimum method with random sampling. The proposed approach offers hitherto unknown insights although it is a generic view system that does not leverage the interests of education experts in focused analysis of the specific category of learners. The system also handles large amounts of dynamically shifting data including data structures as well as user evaluation metrics.

From a different perspective, Pilkington et al. [40] conducted a qualitative study as part of funded research at a UK university with a sample of 75 researchers, tutors, and professors. They used a combination of "systematic, sequential, explanatory and, thematic" approaches to focus on findings from thematic analysis. They identified engagement, attendance, workload, family pressure, and mental health as factors that continue to contribute to dropout issues regardless of university engagement efforts. Apart from these factors, the sense of community, institutional social-environmental contribution, and academic integration are other critical factors contributing to students' retention and dropout [41]. It is therefore essential to go beyond basic AI modeling for predicting dropout, and analyze the impact of ambient socio-economic, psychological, demographic, and family factors to be able to conduct a determined analysis of the causes of dropout. For example, the temporal and disparate nature of MOOCs data, and the inconsistent learner activities therein such as watching and re-watching a video or posting forum feedback as well as associating learning activities with dropout potential that involves personal reasons is a very difficult task as these reasons are "diverse and highly personalized". Chen et al. [38] applied visualization analytics methods and techniques (DropoutSeer) to analyze large datasets from MOOC systems to 
Table 3: Summary of tools/platforms for students' retention, drop out and performance prediction.

\begin{tabular}{|c|c|c|}
\hline Tool/platform & $\begin{array}{l}\text { Provider } \\
\end{array}$ & Key Features \\
\hline CampusLabs [44] & CampusLabs & $\begin{array}{l}\text { - Integrates data from different sources to cultivate campus in- } \\
\text { telligence and make better decisions. } \\
\text { - Identifies students at risk } \\
\text { - Special supports for targeted students } \\
\text { - Strengthen educators' ability to guide students on their path- } \\
\text { ways for success. }\end{array}$ \\
\hline $\begin{array}{lc}\text { RNL } & \text { Student } \\
\text { Retention } & \text { Predic- } \\
\text { tor [45] } & \\
\end{array}$ & RNL & $\begin{array}{l}\text { - Poses accurate assessment capabilities and extracts actionable } \\
\text { insights from data obtained from different sources a } \\
\text { - Its predictive analytics identifies students who need special } \\
\text { attention and help } \\
\text { - Helps in developing strategies that increase efficiency and the } \\
\text { impact of retention efforts } \\
\text { - Helps administration to recruit and retain the right students }\end{array}$ \\
\hline $\begin{array}{ll}\text { Nuro } & \text { Reten- } \\
\text { tion [46] } & \end{array}$ & Nuro & $\begin{array}{l}\text { - Efficient predictive analytics helps educators in engaging each } \\
\text { student } \\
\text { - Identifies students at the risk and also provides insights on } \\
\text { the reasons for it } \\
\text { - Helps educators in devising strategies and acquiring tools and } \\
\text { other resources that will have a positive impact on students' } \\
\text { graduation and retention results } \\
\text { - Can be customized to an institution's needs }\end{array}$ \\
\hline $\begin{array}{l}\text { Othot Retention } \\
\text { Predictor }[47]\end{array}$ & Othot & $\begin{array}{l}\text { - Real time and dynamic predictions } \\
\text { - Identifies the individuals who needs more attention } \\
\text { - Recommends actions and devise strategies that will have the } \\
\text { greatest impact on an individual's performance } \\
\text { - Affordable tool showing educators where to focus resources }\end{array}$ \\
\hline $\begin{array}{l}\text { CampusNexus Suc- } \\
\text { ceed }[48]\end{array}$ & $\begin{array}{l}\text { Campus Manage- } \\
\text { ment }\end{array}$ & $\begin{array}{l}\text { - Tracks each students engagement and progress } \\
\text { - Identifies and prioritizes students based on the risk level } \\
\text { - Flags and allows a teacher to respond to alerts from other } \\
\text { teachers }\end{array}$ \\
\hline
\end{tabular}

correlate (ML) predicted dropout rates with learning activities of MOOC subscribers visually. The aim was to enable content designers to design more suitable, engaging content and AI experts to design better predictive models [42]. This was shown to be more effective, for instance, than the process of feature identification as a critical step in the model building process [43].

The research efforts in students' retention and dropout prediction resulted in several automatic tools to facilitate educational interventions and remedial actions promptly. A summary of some of the existing AI-based tools and platforms for students' retention, drop out and performance prediction has been provided in Table 3 .

\subsection{Personalized Learning}

Personalized Learning has been subject to many simultaneous and fundamental transformations driven by student needs, state needs, internationalization, and globalization as well as education management and technology developments. Technology implementation and inclusion notwithstanding, the traditional learning approach with a static, unidirectional model including teacher in front of students, reading text material and written exam based assessments that cover all sections of the classroom uniformly is being eroded. Contemporary learning directions converge to interactive, student-focused, tailored learning models that serve each student or student group much closer with better engagement, closer interaction, improved comprehension, and wider scope coverage of learning outcomes. The flipped classroom constitutes one of the important learning methodology shifts that started to feature more 
prominently recently with a positive impact on learning practices [49]. Other related developments that give rise to personalized learning include, for example, Competency-Based Learning [50,51], especially in health and medicine education.

The adaptability of the learning model to cater to multiple learning sectors would not have been feasible just a few years ago before the wide availability and accessibility of technology, such as Deep and Reinforcement Learning (RL) which leverages the power of cognitive computing in the support of education. Shawky \& Badawi [52] explore RL as a cognitive computing catalyst to provide adaptive learning materials and paths in support of bespoke, learner-centered requirements. By analyzing the myriad of factors that determine and affect a typical learner's experience and to normalize and monitor the differences between these factors using RL. The outcome is to adapt to the "most influential" of these learning factors per learner needs and learning settings. The authors design a smart learning platform that can recommend appropriate learning material in a connected, continuous way that adapts to the changing needs of the learners; new learner data instances are re-fed to the system using big data analytics as well as learning analytics.

Although not necessarily intended for personalized learning, the flipped classroom constitutes one of the important learning methodology shifts that started to feature more prominently recently with a positive impact on learning practices [49]. In this model, students are exposed to teaching material beforehand and the class time is utilized for open, peer-to-peer problem-solving, case study and brainstorming discussions to consolidate concepts studied independently [53]. With this, the flipped classroom model offers an adaptive learning and teaching model.

Sein et al. [54] illustrate recent advances in educational technology as well as the design of instructional models for facilitating a tailored learning experience for each student. The authors identified several learning advantages to this approach that have a notable positive impact directly affecting final grades as well as attrition and dropout rates through a case-study. Technology plays pivotal roles in the design, operations, feedback analysis of flipped classroom models including analytics which provide insights about time management and commitment from stakeholders. For example, Ahmad et al. [55] analyzed the time management aspects of an undergraduate level engineering course that was run according to the flipped model. By analyzing student learning activities, the authors were able to identify specific patterns of time-management strategies using trace data and were also able to identify strong correlations between time management strategies and academic performance. Digital technology plays a major role as a catalyst for the transformation in education. For example, Pedro et al. [56] describe the close relationship between technology and pedagogy in support of tailored learning experiences and promote the utilization of data (science) as a platform for the provision of "richer actions".

As part of the efforts several personalized learning tools and platforms relying on AI algorithms have been developed to scaffold instruction based on the student's previous knowledge and level of understanding. Some of the 
existing AI-based educational tools and platforms that support personalized learning are provided in Table 4.

Table 4: Summary of AI based tools/platforms for personalized learning.

\begin{tabular}{|c|c|c|c|}
\hline Tool/platform & Provider & Domain & Key Features \\
\hline $\begin{array}{l}\text { Third Space } \\
\text { Learning [57] }\end{array}$ & $\begin{array}{l}\text { Third } \\
\text { Space } \\
\text { Learning }\end{array}$ & Math & $\begin{array}{l}\text { - Special attention to target students based on } \\
\text { their weaknesses } \\
\text { - Provides weekly online lessons } \\
\text { - Personalized learning by adapting the tutor to } \\
\text { a student's needs with weekly reporting } \\
\text { - Provides access to premium maths resources }\end{array}$ \\
\hline Alta $[58]$ & Knewton & $\begin{array}{l}\text { Math, } \text { statis- } \\
\text { tics, eco- } \\
\text { nomics and } \\
\text { chemistry }\end{array}$ & $\begin{array}{l}\text { - Available for multiple courses including mathe- } \\
\text { matics, statistics, economics and chemistry. } \\
\text { - Provides personalized content in terms of text, } \\
\text { visual and audio } \\
\text { - Affordable and world-wide accessible } \\
\text { - Provides secure and turnkey integration with } \\
\text { any learning management system }\end{array}$ \\
\hline EnLearn [59] & EnLearn & Generic & $\begin{array}{l}\text { - Personalized content via an adaptive learning } \\
\text { ecosystem involving students, teachers and cur- } \\
\text { riculum } \\
\text { - Can increase content for target students } \\
\text { - Able to identify misconception and remedies in } \\
\text { the learning process }\end{array}$ \\
\hline $\begin{array}{l}\text { Watson Content } \\
\text { Analytic [60] }\end{array}$ & IBM & Generic & $\begin{array}{l}\text { - Vocabulary learning applications } \\
\text { - Helps teachers to track students' progress } \\
\text { - Conducts real time assessments and provides in- } \\
\text { sights to instructors } \\
\text { - Addresses the high-tech skills gap }\end{array}$ \\
\hline Querium [61] & Querium & Generic & $\begin{array}{l}\text { - Uses AI to help students with STEM skills so } \\
\text { they can be ready for further studies } \\
\text { - A personalized program is called StepWise and } \\
\text { it works on smartphones and computers } \\
\text { - Delivers personalized, bite-sized lessons and } \\
\text { step-by-step tutoring assistance }\end{array}$ \\
\hline Edly [62] & ArbitSoft & Generic & $\begin{array}{l}\text { - Supports students of all ages including } \mathrm{K}-12 \\
\text { and Higher education } \\
\text { - Provides training management of different } \\
\text { stack-holders of the education }\end{array}$ \\
\hline Squirrel [63] & Squirrel & $\begin{array}{l}\text { Math, } \\
\text { English, } \\
\text { Physics, } \\
\text { Chemistry }\end{array}$ & $\begin{array}{l}\text { - Squirrel AI Learning offers the high-quality } \\
\text { after-school courses in subjects such as Chinese, } \\
\text { Math, English, Physics, and Chemistry. } \\
\text { - Provides students with a supervised adaptive } \\
\text { learning experience }\end{array}$ \\
\hline MobyMax [64] & MobyMax & $\begin{array}{l}\text { all K-8 sub- } \\
\text { jects }\end{array}$ & $\begin{array}{l}\text { - Uses AI to pinpoint and fix learning gaps with } \\
\text { adaptive, differentiated learning materials for } \\
\text { all K-8 subjects. } \\
\text { - Students can learn at their own pace with les- } \\
\text { son plans and practice with automatically gen- } \\
\text { erated sheets. }\end{array}$ \\
\hline Kidaptive [65] & Kidaptive & - & $\begin{array}{l}\text { - Rich analytics allows to better understand and } \\
\text { improve the usage and engagement } \\
\text { - Provides actionable insights to all stack- } \\
\text { holders, such as parent, teachers and adminis- } \\
\text { trators, about learning } \\
\text { - The real-time adaptivity allows it to adjust to } \\
\text { learners' requirement and provide optimally en- } \\
\text { gaging materials }\end{array}$ \\
\hline Century Tech [66] & $\begin{array}{l}\text { Century } \\
\text { Tech }\end{array}$ & - & $\begin{array}{l}\text { - Combines cognitive neuro-science and data an- } \\
\text { alytics for creation of personalized learning ma- } \\
\text { terials } \\
\text { - Facilitates teachers in planning, grading and } \\
\text { checking/managing students' homework } \\
\text { - Keeps track of students' progress, identifies } \\
\text { knowledge gaps and personalized study mate- } \\
\text { rial }\end{array}$ \\
\hline
\end{tabular}

\subsection{Students' Performance Prediction}

To be able to predict a student's likely future performance in a course can provide very powerful platforms that facilitate educational interventions and 
remedial actions promptly. The development of AI models for the prediction of student performance and uncovering hidden insights and patterns are some of the most salient applications and research areas in EDM. Several studies have been conducted in the area of academic performance analysis and prediction, including by Adejo et al. [67], who conducted an empirical investigation and comparison of several data sources, classifiers, and ensembles of classification techniques to predict the academic performance of university students. In detail, they compared and analyzed the performance of ensemble techniques combining information from different data sources against the models trained on data from a single source. To this aim, several algorithms including DT, ANNs and SVM were used and compared individually as well as in ensemble (combination) modes. Their findings support the premise that multiple data sources in combination with heterogeneous ensemble ML techniques provide efficient models for predicting student performance and also for identifying students at risk of attrition. Livieris et al. [26] also proposed an ensemblebased semi-supervised approach for predicting student performance achieving sufficient accuracy in early prediction of student progress. Khan et al. [68] designed an AI model targeting students in introductory programming modules to notify them about their probable outcomes early on in the academic semester. To notify the students about their probably final result given their current results as well as academic behavior, and to enable the student to make corrective measures to improve their expected performance results. In total, they employed eleven ML models grouped in five categories, where overall better results have been obtained with Decision Tree (J48) in terms of accuracy and F-Measure.

Deep learning techniques were also employed to tackle the challenging problem of forecasting the future performance of students. For instance, Kim et al. [69], proposed GritNet, a novel deep learning model, for the prediction of students' performance by treating it as a sequential prediction task. GritNet is mainly based on the bidirectional long short term memory (BLSTM). The authors applied the model to a group of Udacity students to predict their graduation predictions and were able to show favorable results of logistic regression models with on-the-ground improvements in the early weeks of the course which are traditionally the most challenging to predict.

\subsection{Sentiment Analysis in Education}

Sentiment Analysis attempts to improve the learning process by analyzing students' feedback to better understand their opinion and make adjustments to the content or delivery of the learning material accordingly [70]. Sentiment Analysis plays a significant role to account for the effects of social media as a platform for airing students' opinions of the learning process; a major metric in the assessment of learning. From a MOOCs perspective, Kastrati et al. [71] assert the valuable insights of Sentiment Analysis in student feedback while at the same time highlighting the great difficulty in assessing their feedback 
about the learning process with human intervention. Hence they propose an Aspect-Level Sentiment Analysis framework specifically aiming to highlight polarity in student feedback about MOOCs. Liu et al. [72] argue that the "temporal nature" of student feedback in MOOCs environments stipulates that students' emotions and learning activities be tracked for understanding learning requirements. To classify emotional aspects of students, the authors propose a Temporal Emotion-Aspect Model (TEAM) which tracks emotions over time with two main outputs: a) aspect probabilistic distributions that are emotion-specific and b) their time-based evolution, which uncovered emotional salient student emotions as well as their evolutionary trends. The results indicated that: (i) content-related aspects were the main emphasis with higher likelihood to confused or negative emotions; (ii) there were higher likelihoods of emotional expressions at the start and end of a semester; (iii) under-achieving students were less active in emotional engagement and tended to express more confusion towards the end of a semester when compared to high-achieving and medium-achieving students.

There is a significant amount of literature on the topic generally involving analysis of students generated text or their social media posts about curriculum, teaching methodology and materials [73]. For instance, Munezero et al. [74] analyzed students' learning diaries to predict students' sentiments, emotions, and opinions about their learning experience. According to Kechaou et al. [75], knowledge and evaluation of user opinions is an essential prerequisite for the effective development of e-learning systems. To this end, an opinion mining method has been applied in their research to support e-Learning content developers to enhance the quality of provided services using three feature selection methods, namely Mutual Information (MI), Information Gain (IG), and CHI statistics (CHI) in conjunction with HMM and SVM-based hybrid learning methods. Experimental results indicating that opinion mining is more challenging in e-learning blogs. Although this work has shown that IG constitutes the optimal potential for sentimental term selection and produced optimum accuracy in sentiment classification. More recently, Mostafa et al. [76] reviewed work in sentiment analysis related to Gamification in learning, the author proposed a Classifier that will analyze the sentiments of students while using Gamification tools for learning in Egypt.

The research efforts in the domain resulted in several interesting AI-based sentiment analysis tools. Some of the existing sentiment analysis tools developed or customized for education are provided in Table 5.

\subsection{Recommendation Systems in Education}

With the advances in design and accessibility of AI packages and tools, it has become quite attainable to incorporate AI services with Learning Management Systems (LMS) that store and collate student assessment results and provide basic analytics and reports to academic managers either for daily operations processes or for local, regional or international quality assurance and accred- 
Table 5: Summary of tools/platforms for sentiment analysis in education.

\begin{tabular}{|c|c|c|}
\hline Tool/platform & Provider & Key Features \\
\hline Pepper $[77]$ & $\begin{array}{l}\text { SoftBank } \\
\text { Robotics }\end{array}$ & $\begin{array}{l}\text { - Can answer visitors'/costumers' queries } \\
\text { - Helps administrative staff to performing routine tasks } \\
\text { - Engages visitors in an effective conversations and provides } \\
\text { personalize responses }\end{array}$ \\
\hline NAO [78] & $\begin{array}{l}\text { SoftBank } \\
\text { Robotics }\end{array}$ & $\begin{array}{l}\text { - Informs and entertain visitors } \\
\text { - Provides an optimized teaching-aid tool } \\
\text { - Efective tool for special education ("students with disabilities } \\
\text { such as autism, emotional and behavioural disorders" [79]) }\end{array}$ \\
\hline $\begin{array}{l}\text { ZimGo Emotional } \\
\text { Intelligence }[80]\end{array}$ & ZimGo & $\begin{array}{l}\text { - Recognizes and differentiates in human emotions from text } \\
\text { - Employs state-of-the-art AI and NLP techniques } \\
\text { - Poses Contextual Analysis capabilities } \\
\text { - Can be customized for any application }\end{array}$ \\
\hline Talkwalker [81] & Talkwalker & $\begin{array}{l}\text { - An effective social listening and analytics tool } \\
- \text { Helps educators to promote their college and university } \\
\text { - Poses user-generated content detection capabilities } \\
\text { - An influencer identification tool }\end{array}$ \\
\hline
\end{tabular}

itation aims [82]. The branch of LMS evolution that goes in connection with $\mathrm{AI}$ is an intelligent tutoring system (ITS), which has demonstrated greater achievement when compared to traditional classroom instruction and studies from printed materials [83].

Applying data mining and AI algorithms to recommend remedial actions in support of learning quality is an obvious choice in support of the operational side of academic teaching [84]. In this environment, assessment data collected over several academic semesters are grouped by learning outcomes at the course and program levels. Historical student attainment shortcomings that are typically remedied with domain experts and course coordinators are gathered for learning, wherein a pool of remedial actions (recommendations) is gathered over 3 to 5 years [85]. Training data/features, such as course domain, course level, section size, and lab option, are sufficient to guide experts to choose a remedial action that is recommended for subsequent assessments; formative or summative. A multi-label classification algorithm is then used to select appropriate actions for each rubric line (performance per group of students) from the master pool. AI provides obvious strengths in this application domain and is manifested with efficiency, consistency, and fairness in the application of remedial actions. Although to achieve optimum performance such a setup is most appropriate for massive colleges with thousands of students and availability of archives of structured, outcome-based, assessment data for several years, nonetheless the approach was sound and successful with reasonable accuracy even with a few thousand learning instances.

Being one of the key applications, several interesting recommender systems are developed to facilitate educators. The tool help learners to choose quality learning materials. Several recommendation tools are available for students in different domains. Table 6 summarizes some existing recommendation systems in education for both students and teachers.

\subsection{Classroom Monitoring and Visual Analysis}

Classroom utilization and occupancy calculations are part of budgetary planning and strategic planning of higher education institutes, especially where real 
Table 6: Summary of AI based tools/platforms for recommendation systems in education.

\begin{tabular}{|c|c|c|}
\hline Tool/platform & Provider & Key Features \\
\hline Qbot $[86]$ & $\begin{array}{l}\text { Antaras (in col- } \\
\text { laboration with } \\
\text { Microsoft and } \\
\text { UNSW, Sydney) }\end{array}$ & $\begin{array}{l}\text { - Tags tutors and classmates to answer students' questions } \\
\text { - Recommends contents individual students based on their cur- } \\
\text { rent level of knowledge } \\
\text { - Provides students' analytics }\end{array}$ \\
\hline MyEdMatch [87] & MyEdMatch & $\begin{array}{l}\text { - Connects schools and teachers having shared beliefs and goals } \\
\text { - Helps schools to recruit best talent } \\
\text { - Helps teachers in searching jobs }\end{array}$ \\
\hline TeacherMatch [88] & Power School & $\begin{array}{l}\text { - Uses AI for real-time analysis of the candidates in the pool } \\
\text { maintained by the platform } \\
\text { - Assess teachers on four factors including teachers' qualifica- } \\
\text { tion, teaching skills, cognitive abilities and attitudinal factors }\end{array}$ \\
\hline
\end{tabular}

estate is a premium asset [89]. Students in modern offline or online degrees have many technology-driven advantages at their fingertips but equally, suffer excessive demands which often cause dropouts and classroom under-utilization. Although predicting room occupancy/utilization is an age-old problem [90], the use of modern AI technology as instruments in measuring or increasing the efficiency of room utilization is a new topic. Sutjaritthamet et al. [91] used on-campus sensor instruments to monitor classroom attendance while respecting student privacy. Several measurement approaches were evaluated in a lab experiment to identify the best sensor technology in terms of cost, accuracy, and convenience.

AI also has an impact on TEL by providing several interesting applications in many sub-domains. One such area is to aid in the understanding of the difficult task of understanding the various dimensions of TEL in schools. One reason for this difficulty is the limitation of monitoring classrooms for a longer period to analyze teachers' teaching methods and students' learning experience. Howard et al. [92] explored the area of observing, analyzing, and visualizing TEL classrooms over time and used sensors to collect observation data over two months. This data is presented as insights to academic administrators and teachers for reflection and corrective action to enhance student learning. AI and EDM approaches are deployed to handle the complex learning aspects in a TEL environment at a higher level of precision.

Other applications of EDM and AI for the transformation of the traditional classroom include the analysis of student facial expressions to assess their level of engagement in the classroom. Soloviev et al. [93] proposed a system that analyzes (in real-time) the data feeds from video cameras that are installed in the classroom and apply AI and facial recognition technology to recognize student emotions to determine their level of enjoyment. Although the bulk of research focus tends to be on MOOCs, digital and online learning environments because of the massive data they generate, nonetheless the physical classroom has been the focus of much research recently as well. Chua et al. [94] reviewed case studies and technologies developed to collect and analyze educational data. Several aspects of the learning environment, which is a combination of the physical and digital classroom setting, are studied. Moreover, different aspects of the learning process are assessed and analyzed to quantify teaching and learning processes, student assessments are also ana- 
Table 7: Summary of AI based tools/platforms for Classrooms' Monitoring and Visual Analysis

\begin{tabular}{|c|c|c|}
\hline Tool/platform & Provider & Key Features \\
\hline $\begin{array}{l}\text { Jibble Attendance } \\
\text { Platform }[95]\end{array}$ & Jibble & $\begin{array}{l}\text { - Provides an accurate attendance mechanism with bio-metric } \\
\text { verification } \\
\text { - Tracks attendance with Phones and Tablets } \\
\text { - Prevents cheating with the use photos, facial recognition and } \\
\text { GPS } \\
\text { - Generates automatic attendance sheets and reports with ac- } \\
\text { tionable insights }\end{array}$ \\
\hline LoopLearn [96] & LoopLearn & $\begin{array}{l}\text { - Provides secure and efficient roll marking facilities by allowing } \\
\text { designated school staff only to access the tool } \\
\text { - Generates automatic attendance sheets and reports with ac- } \\
\text { tionable insights } \\
\text { - Can be customized to the needs of other departments of a } \\
\text { school, such as sports, peripatetic and excursions by adding } \\
\text { additional features }\end{array}$ \\
\hline $\begin{array}{l}\text { Secure Accurate } \\
\text { Facial Recognition } \\
(\text { SAFR) }[97]\end{array}$ & SAFR & $\begin{array}{l}\text { - A general purpose AI based facial recognition } \\
\text { - The tool is customized for K-12 schools with facial recognition } \\
\text { of students' parents to allow them to enter the school }\end{array}$ \\
\hline AirClass [98] & AirClass & $\begin{array}{l}\text { - Analyze students' response to a lecture automatically } \\
\text { - Detects whether students' eyes are opened or closed during a } \\
\text { lecture } \\
\text { - Also analyzes students' interests and commitment in learning } \\
\text { through facial emotion recognition and analysis. }\end{array}$ \\
\hline $\begin{array}{l}\text { Captemo: Emotion } \\
\text { Recognition [99] }\end{array}$ & Captemo & $\begin{array}{l}\text { - A general purpose tool that analyzes customers' experience } \\
\text { through emotional intelligence } \\
\text { - Embedded with state-of-the-art facial and emotion recognition } \\
\text { algorithms } \\
\text { - Supports both: a continuous and on-demand monitoring capa- } \\
\text { bilities }\end{array}$ \\
\hline BliPPAR [100] & BliPPAR & $\begin{array}{l}\text { - Improves students' creativity, interactivity and engagement to } \\
\text { any subject with the help of computer vision and augmented } \\
\text { reality. } \\
\text { - Provides better visualization of complex topics } \\
\text { - Helps in creating interactive learning materials }\end{array}$ \\
\hline
\end{tabular}

lyzed automatically. The authors introduce data pipelines that leverage data and information collected from both physical spaces as well as digital spaces.

As part of the efforts, several AI-based tools are developed that can help in classrooms in several ways, such as security, marking attendance rolls, and emotional and movement monitoring for better classroom dynamics analysis. Table 7 summarizes some of the existing classrooms monitoring systems.

\subsection{Intelligent Tutoring Systems (ITS)}

ITS systems can be differentiated from personalized learning platforms as they represent a specialized concept/component in personalized learning, and there's dedicated literature on it. Since ITS is a very well developed form of personalized learning platforms and therefore we describe it in a distinct section. ITS, which aims to provide immediate and customized feedback to learners, play a major role to plug the growing gap between the increasing number of learners and the shortages in qualified specialist teachers globally. AI is also very effective in predicting student cognitive needs, results, mental states, and skills and subsequently recommending the right course of action. For example, ITS with AI enhancements are applicable in modelling student emotions [101], efficacy [102], ability to perform scientific enquiry within a virtual environment [103] and then generate recommendations automatically [104]. Although ITS research is yet to refine the mapping between the what, how explanations of Intelligent Pedagogical Agent (IPA) system decisions and actions on the 
one hand and students or teachers on the other, the role of AI techniques and models interpretability is even more essential within these contexts of modern learning. This is because it enables an IPA to justify actions and inferences. This, in turn, improves IPAS' effectiveness (providing "why" analysis rather than merely "what"). Furthermore, this fosters user trust and confidence in the correctness and integrity of the learning system [105]. The branch of ITS research about interpretable student and learning models is Open Learner Models [106].

Open Learner Models (OLM) which stem from ITS aim to open up AI learner models in terms of human cognition, learning and teaching. While ITS research focuses on how AI can be used in education effectively, OLM research focuses on the essential components needed to make AI models interpretable and explainable in the context of learning. Interpretable AI as such can provide a framework for the implementation of knowledge-based and AI systems in education and beyond. Interactive and personalized learning $[107,108]$ models require IPAs that predict and respond to learner backgrounds, skills and attitudes [109].

Student Models play many roles within ITS including for assessment of student performance in core or soft skills or for monitoring student compliance with curriculum of school constraints during their path/plan of study. This variety of purpose shapes the fundamental design of the student model's architecture and opens up this field for quite rich research and applications design. The authors in [110] analyze student models in ITS from the perspective of them forming a component in the architecture of an ITS and also for determining the model components that should be considered in its design. Using a conversational ITS (CIRCSIM-Tutor), the authors define the decisions that the system needs to make together with the associated information that supports these decisions. The authors recommend four types of student model blueprints that are based on information aspects and constraints of the tutoring system being analyzed.

According to [111], although the important role Student Models plan within ITS from a problem solving perspective is a given fact, the authors focus is in the little attended area of tailored instruction mechanisms in ITS that engage students in conceptual discourse utilizing natural language, known as Tutorial Dialogue Systems (DTS). Using conceptual physics as an application domain, the authors introduce a TDS that maps tutorial dialogues and student models; their (RIMAC) model dynamically build a persistent student model that supports proactive as well as reactive decisions in service of adaptive student instruction. In applied classroom and test pilot studies, the authors demonstrated the effectiveness of their DTS with students taking less time to complete learning tasks than counterparts who did not utilize the system in tutorials. It was also demonstrated that "both high and low prior knowledge students learned more efficiently from a version of the tutor that dynamically updates its student model during dialogues than from a control version that included the static (poor man's) student model." 
Table 8: Summary of AI based tools/platforms for Intelligent Tutoring Systems.

\begin{tabular}{|c|c|c|c|}
\hline Tool/platform & Provider & Domain & Key Features \\
\hline DreamBox [112] & $\begin{array}{l}\text { DreamBox } \\
\text { Learning }\end{array}$ & Math & $\begin{array}{l}\text { - Available in two languages namely English and } \\
\text { Spanish } \\
\text { - Provides a game-like environment, engaging } \\
\text { students in analytical problems, with predictive } \\
\text { insights } \\
- \text { Pinpoints real time data and academic insights } \\
- \text { Customized professional development aligned } \\
\text { with curriculum } \\
- \text { Posses the ability to dynamically adjust to stu- } \\
\text { dents' actions by providing personalized con- } \\
\text { tent and feedback in real-time. } \\
\text { - Facilitates and motivate students for learning } \\
\text { in both in-class and distance learning. }\end{array}$ \\
\hline MATHia [113] & $\begin{array}{l}\text { Carnegie } \\
\text { Learning }\end{array}$ & Math & $\begin{array}{l}\text { - Delivers a successful math experience to each } \\
\text { individual student } \\
\text { - Provides teachers with a real-time feedback and } \\
\text { assessments of their students } \\
\text { - Allows both students and teach- } \\
\text { ers/administrators to visually monitor } \\
\text { their/students' progress towards different } \\
\text { skills } \\
\text { - Facilitates the teachers get alerts when a stu- } \\
\text { dent idle or needs additional support or a stu- } \\
\text { dent achieves a learning milestone. }\end{array}$ \\
\hline STMath [114] & $\begin{array}{lc}\text { MIND } & \text { Re- } \\
\text { search } & \text { In- } \\
\text { stitute } & \end{array}$ & Math & $\begin{array}{l}\text { - Can be used by the administrators, teachers and } \\
\text { parents to track students' knowledge } \\
\text { - An attractive user interface involving students } \\
\text { in learning through solving puzzles and chal- } \\
\text { lenging problems } \\
\text { - Provides valuable feedback to learners on their } \\
\text { approaches } \\
\text { - Allows the teachers/schools to monitor stu- } \\
\text { dents' performance }\end{array}$ \\
\hline $\begin{array}{l}\text { ASSISTments } \\
{[115]}\end{array}$ & $\begin{array}{l}\text { Neil Hef- } \\
\text { fernan }\end{array}$ & $\begin{array}{l}\text { Math, Statis- } \\
\text { tics, English, } \\
\text { and Sceince } \\
\text { etc., }\end{array}$ & $\begin{array}{l}\text { - Blends tutoring with assistance and assess- } \\
\text { ments } \\
\text { - Supports multiple subjects } \\
\text { - Equally useful for teachers and students by pro- } \\
\text { viding teachers with actionable data, and stu- } \\
\text { dents with a real-time feedback } \\
\text { - Allows to develop/assign problem sets to stu- } \\
\text { dents from curricula and textbooks }\end{array}$ \\
\hline Cognizant [116] & Cognizant & Generic & $\begin{array}{l}\text { - Make use of AI to improve students' access to } \\
\text { education (admissions), experience and success } \\
\text { - Provides testing and assessments services } \\
\text { - Personalized content ensuring deep conceptual } \\
\text { understanding on mastery basis where students } \\
\text { can't move to next level without } 100 \% \text { score in } \\
\text { a level } \\
\text { - Provides a flexible instructional tool that can } \\
\text { be integrated/fit into different curriculum im- } \\
\text { plementations. }\end{array}$ \\
\hline
\end{tabular}

Several tools have been developed as a result of the research conducted in these applications over the years. Table 8 provides a summary of the intelligent tutoring systems presented in this work.

\section{Techniques}

The literature on AI in education based on the nature of the AI algorithms can be roughly divided into three main categories, namely (i) Supervised ML, (ii) Unsupervised ML, and (iii) Reinforcement learning. In the next sub-sections, we provide a brief description of each of the ML algorithms category. Moreover, detailed statistics of techniques in each application are provided in Section 4. 


\subsection{Supervised Learning}

The majority of the works on AI in education rely on supervised learning as detailed in Section 4. Supervised learning aims at function approximation or cure fitting by finding a relation/function $f: x \rightarrow y$ using a training set $\{x, y\}$. Though the efficiency of supervised learning largely depends on the availability and quality of training data, it is a far more accurate learning strategy compared to its counterparts [117]. Supervised ML algorithms can further be divided into several categories at different hierarchies. A complete taxonomy of supervised learning techniques can be found in [117]. Some wellknown techniques include Random Forests (RF), Conditional Random Forests (CRFs), SVMs, Decision Trees, Neural Networks (NNs), Logistics and Linear Regressions, Belief Networks, Naive Bayes and Markov Random Fields and Markov models.

In education, supervised learning is mostly used in predictive analysis, such as grading [118], retention, and dropout prediction [119, 120]. For instance, Majeed et al. [118] proposed several supervised learning techniques for students' grade prediction. In detail, around 2500 students' records were collected from a degree-awarding institution to train different supervised learning algorithms including Naive Bayes and K-nearest Neighbour classifiers. Similarly, in [119], several supervised learning algorithms including Decision Tree-based algorithms, Naive Bayes, k-NN, Linear Models, and Deep Learning, are employed for the identification of students at risk using around 15,825 samples from Budapest University of Technology and Economics.

One of the main limitations of a supervised learning-based strategy in the education sector is the availability of a large number of quality training samples as detailed in Section 5. In order to overcome these limitations, a modified form of supervised learning, namely semi-supervised learning aiming to exploit partially labeled train sets for the classification tasks, has been introduced. For instance, Livieris et al. [26] proposed a semi-supervised learning-based framework for secondary school students' performances.

\subsection{Unsupervised Learning}

Unsupervised learning, which aims to discover or extract patterns of regularities and irregularities in a set of observations, has also been widely exploited in educational data analysis. Unsupervised algorithms process and discover hidden patterns in input samples without needing any training samples, and thus are easy to implement and deploy in an application. Unsupervised ML algorithms can be mainly divided into two categories, namely (i) clustering and (ii) dimensionality reduction techniques, which are further divided into subgroups. A detailed taxonomy of unsupervised ML algorithms has been provided in [117]. Clustering algorithms aim to divide a collection of samples into clusters or segments while dimensionality reduction algorithms are used to 
extract a smaller but more relevant set of features for building a more reliable model.

In the literature, unsupervised learning - especially clustering algorithmshave been mostly used in educational data mining to extract useful information for a diverse set of applications from raw data [121]. Some of the applications of educational data mining in which clustering has been proved very effective include students' performance prediction [122], students' profiling and modeling [123], recommendation systems for students and instructors [124], enrollment management [125], constructing course contents [126] and analyzing students' behaviour [127]. Similarly, dimensionality reduction algorithms, such as Principal Component Analysis (PCA) and Linear Discriminant Analysis (LDA), have also been employed in educational data analysis. For instance, Borges et al. [128] employed PCA for students' performance prediction and data analysis.

\subsection{Reinforcement learning}

In the beginning, reinforcement learning was mostly restricted to robotics and game theory, however, more recently it has been deployed in other application domains as well [117]. A significant portion of literature, especially the work presented in top venues as detailed in Section 4, is based on reinforcement learning. Reinforcement learning provides a set of recommended actions to maximize reward in a particular situation/application. Reinforcement learning differs from supervised learning in several ways. For instance, supervised learning algorithms are trained on class labels to predict a class while reinforcement learning algorithms are trained on a reward signal and predict/recommend an action to solve a particular problem. Moreover, reinforcement learning performs a task in a sequential way where the input depends on the previous decision.

Similar to supervised and unsupervised learning, reinforcement learning algorithms can be divided into different categories. Reinforcement learning algorithms can mainly be categorized as Markovian or evolutionary. A complete taxonomy of reinforcement learning can be found in [117].

In education, reinforcement learning has been mainly used for generating feedback for students on time series data [129], modeling students' learning style [130], personalized learning [131], adaptive tutorial modeling [132] and improving students' problem solving capabilities [133].

\section{Bibliometric Analysis}

In the bibliometric analysis, we analyze the research trends in AI in education. Such analysis is an integral part of the research evaluation methodology in different domains [134]. We believe the bibliometric analysis of the domain over the last few years could be useful for the community. It will give them an idea of 
the recent trend in the domain. To this aim, we used 3246 articles from the top venues including five conferences and four journals in the domain. The choice of these venues for the study is motivated by a significant portion of the literature covered in these venues. It is to be noted that we used different keywords, such as educational data mining, ML for education, intelligent tutoring systems, intelligent tutor, AI tutor, AI for education, ML for education, intelligent classroom, etc., to collect papers from these venues.

Some statistics of the data used in the analysis is provided in Table 9, which include 663 articles from the International Conference of Educational Data Mining (EDM) [14], 87 articles from the Journal of Educational Data Mining (JEDM) [135], 393 articles from the ACM Conference on Learning at Scale (L@S) [136], 406 articles from the International Conference on Learning Analytics \& Knowledge (ILAK) [137], 225 articles from International Conference on Artificial Intelligence in Education (AIED) [138], 235 articles from International Conference on Intelligent Tutoring Systems (ITS) [139], 180 articles from Journal of Learning Analytics (LAK) [140], 740 articles from British Journal of Educational Technology (BJET) [141], and 317 articles from International Journal of Artificial Intelligence in Education (IJAIED) [142]. These numbers from the top venues are expected to provide a reasonable generalization of the research trends in the domain. The data was obtained from various sources, including ACM Digital Library [143], Scopus [144] and CrossRef [145]. Data from the CrossRef repository were scraped using Harzing's Publish or Perish' utility [146]. These data sources allow users to extract data based on different features including author name, affiliation name, source venue name, years, and funding status. We extracted these papers published on above mentioned venues using filters on source venue names irrespective of location of affiliation of the authors. This approach gave us comprehensive dataset of papers covering our considered venues. Finally we did a manual check to confirm that extracted papers do not include any papers from the venues outside our considered list. In detail, we analyze several factors namely (i) authors based productivity analysis, (ii) institution and country based productivity analysis, (iii) knowledge flow by highlighting the cross-references of different venues, the (iv) relationship between the applications and techniques, (v) relationship between applications and venues, and the (vi) relationship between techniques and venues.

Table 9: Statistics of the dataset used for the bibliometric analysis

\begin{tabular}{|c|c|}
\hline Venue & $\#$ Articles \\
\hline Journal of Educational Data Mining & 87 \\
\hline International Conference of Educational Data Mining & 663 \\
\hline ACM Conference on Learning at Scale & 393 \\
\hline International Conference on Learning Analytics & 406 \\
\hline International Conference on Artificial Intelligence in Education & 225 \\
\hline International Conference on Intelligent Tutoring Systems & 235 \\
\hline Journal of Learning Analytics & 180 \\
\hline British Journal of Educational Technology & 740 \\
\hline International Journal of Artificial Intelligence in Education & 317 \\
\hline
\end{tabular}


4.1 Authors based Productivity Analysis

Author productivity is one of the common methods to evaluate significant entities. By consulting the work of top authors in a domain, the directions of a research domain can be easily determined. Figure 1 shows the most publishing authors in the field of AI in education. We observe that authors from USA based organizations are significantly contributing to the field of AI in education. Neil Heffernan from Worcester Polytechnic Institute, Ryan S.J.D. Baker from the University of Pennsylvania, and Kenneth Koedinger from Carnegie Mellon University are collectively ranked as the top three authors in the field of Education Data Mining. Most of the subsequent authors on the list also belong to USA based institutes.

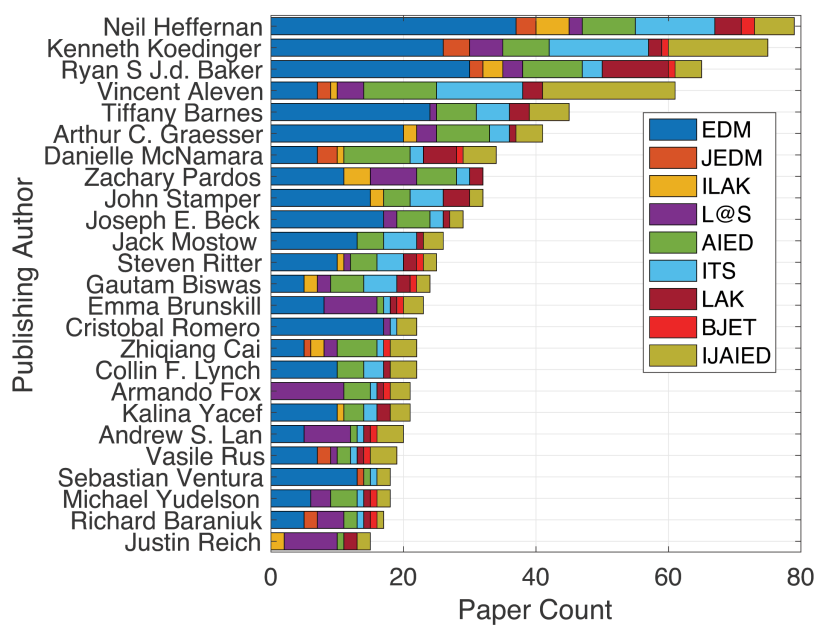

Fig. 1: Authors with the highest publication count during 2014-2020. USA based authors appear to be prominent in this list.

We also observe the trends of co-authorship in AI in education in Figure 2. Median number of authors during 2014-2020 remains more or less constant 3 authors per paper but the spread of authorship increases in recent years. Some papers have experienced a higher number of co-authorship as well, e.g., in 2014 and 2018 maximum number of authors of a paper is 13 authors.

\subsection{Institute and Country based Productivity Analysis}

This subsection deals with the varying research trend of AI in education in different institutes and countries. Figure 3 show the most publishing institutes in the field of AI in education. Almost all of the top institutes are from the 


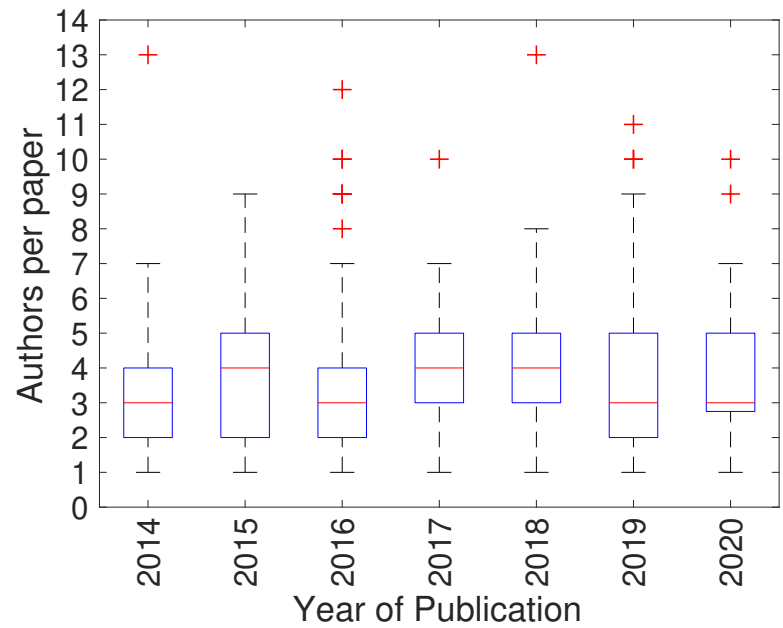

Fig. 2: Distribution of authorship during 2014-2020 in our dataset. Although median number of authors remained more or less constant throughout the mentioned time period but spread of co-authorship increases in recent years.

USA which shows the significant research contributions in this domain by the USA.

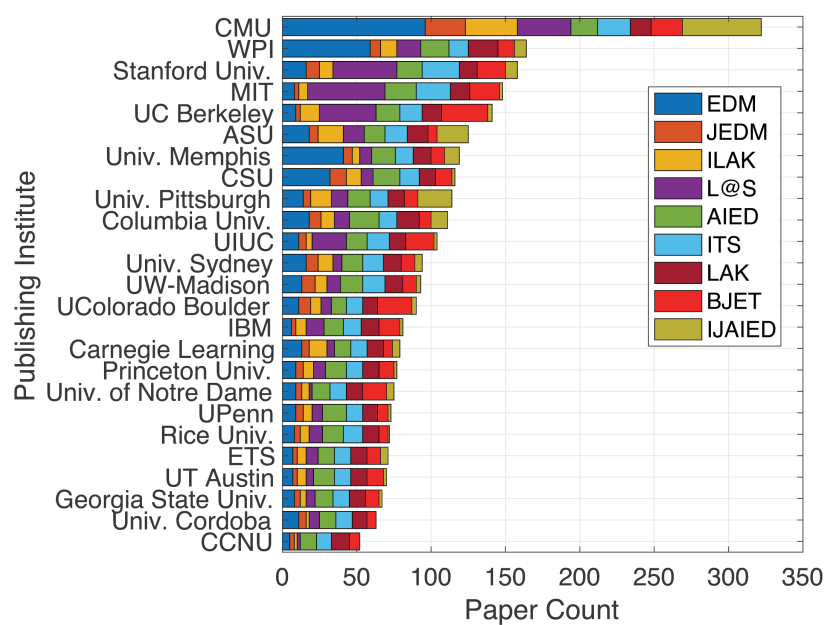

Fig. 3: Institutes with highest number of publications in our dataset during 2014-2020. Almost all of the top publishing institutes are from USA. 
Figure 4 shows the rank of a contributing country in the field of AI in education using a global heat map. The United States is in the highest position in the field of $\mathrm{AI}$ in education in terms of publication count. Other top countries include China, Canada, India, and the United Kingdom in AI in education.

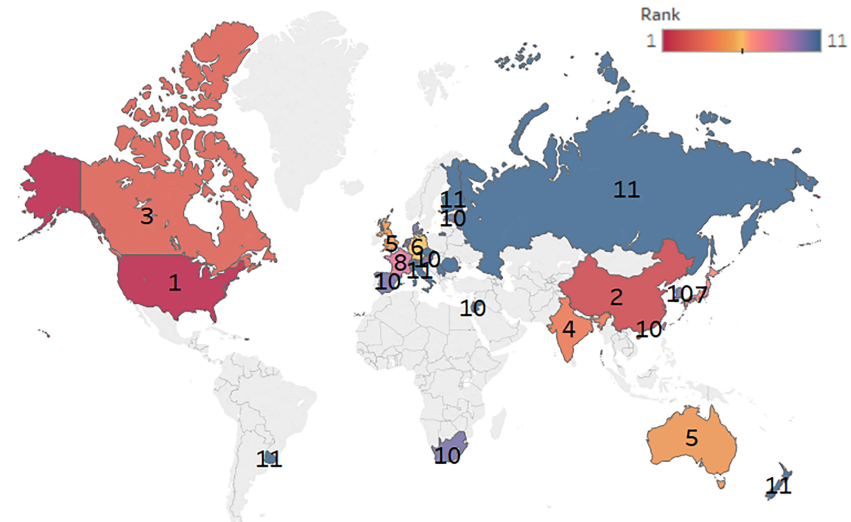

Fig. 4: Rank of countries based on their publication count in our dataset during 2014-2020. USA emerges as top contributor followed by China, Canada, India, and Australia/UK.

\subsection{Knowledge Flow}

First, we extract the references from all papers and create a citation graph, as we are curious to understand how venues in AI in education cite each other. Figure 5 is a Sankey diagram that shows the fraction of papers that AI in education papers reference (left), as well as the other papers that in turn cite the papers in our dataset (right).

Interesting patterns emerge from this analysis. Most noteworthy is the bias for citing papers from the same venue. For example, $26 \%$ of the references in papers for AI in education is for other papers previously published in the AI in education conferences. In contrast, a far more diverse body of papers lists publications from our dataset in their references, particularly other conferences $(57 \%$ of the papers in our dataset which cite AI in education venues are journals, rather than conferences). Major citers of papers in our dataset include Computer \& Education and LNCS (which subsumes many proceedings) besides their selves.

All that said, it is clear that several other publication venues feature heavily in the bibliographies of papers of our dataset, and these are dominated by journals rather than conferences. 


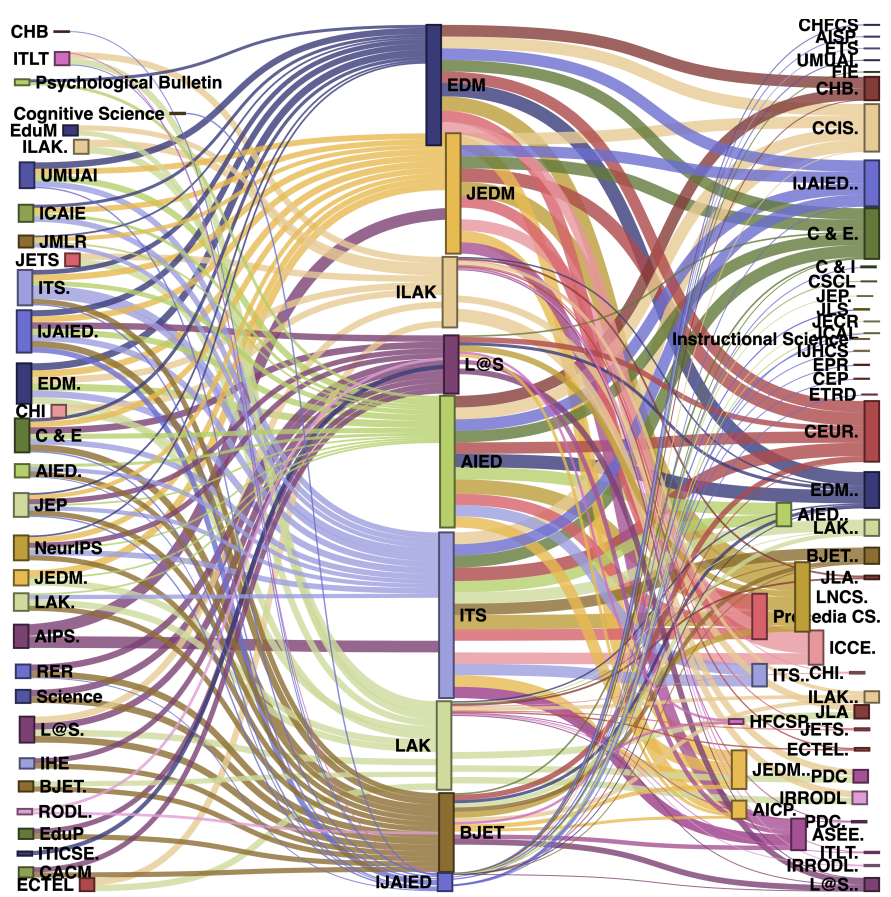

Fig. 5: The distribution references and citations in AI in education venues during 2014-2020. The left input shows the conferences that are referenced by our dataset; the right output shows which papers cite publications in our dataset. Major sources of references and citations in our dataset are from journals.

\subsection{Relationships between Applications and Techniques}

It is also important to provide readers with an overview of AI techniques employed in different applications of AI in education. To this aim, in Figure 6 we provide the statistics of three main categories of AI techniques in terms of the number of publications in different applications in top venues. As can be observed, in most of the applications, supervised or semi-supervised techniques learning have been employed suggesting the availability of the annotated data in the majority of the applications. Unsupervised learning techniques have also been widely employed in some of the applications, such as e-learning, students' evaluation, ITS, and personalized learning. Similarly, reinforcement learning has also been employed in several works on ITS, students' evaluation and retention, and dropout prediction.

\subsection{Relationship between Applications and Venues}

Figure 7 provides the statistics of some interesting applications of AI in education in terms of the number of papers published on each in the leading venues. 


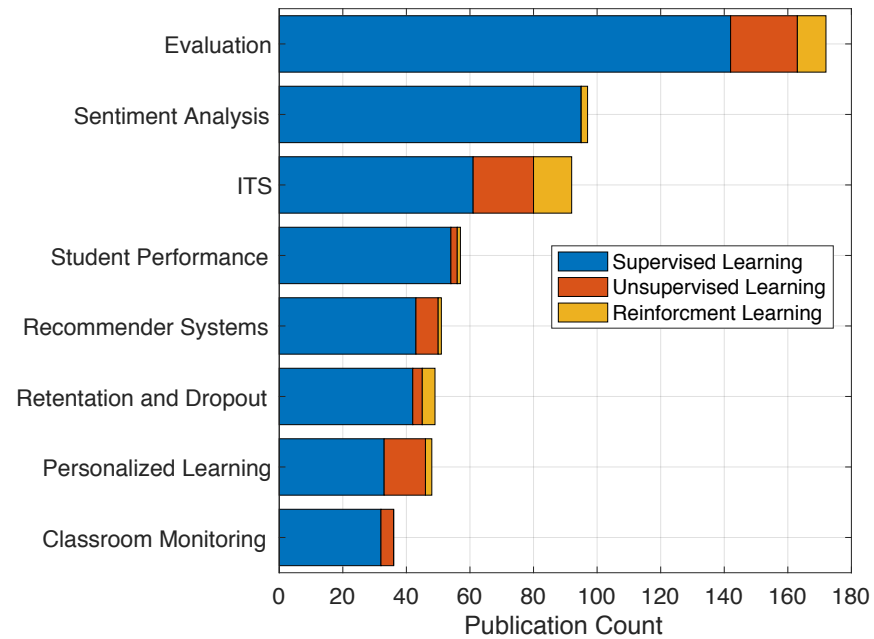

Fig. 6: Relationship between applications and AI techniques.

The most popular application of AI in education is in developing intelligent tutoring systems followed by its use for evaluation and personalized learning.

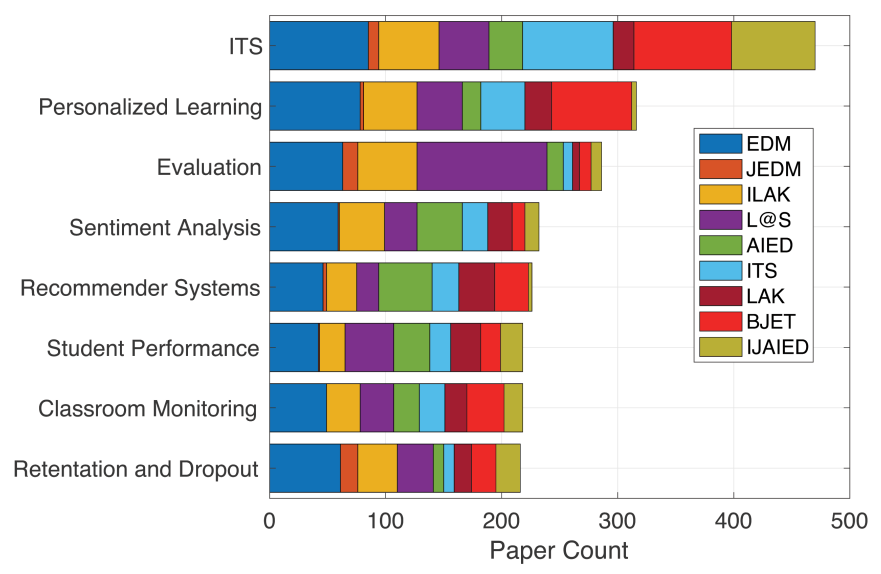

Fig. 7: Statistics of AI papers at top venues in terms of applications. 
4.6 Relationship between Techniques and Venues

Figure 8 shows the statistics of the papers published based on the three types of data-driven AI methods, namely (i) supervised learning, (ii) unsupervised learning, and (iii) reinforcement learning. As can be seen in the figure, algorithms from each of the three categories have been deployed in educational data analysis works presented in the top four venues of the domain. The most common technique type by far is supervised learning followed by unsupervised learning and then reinforcement learning.

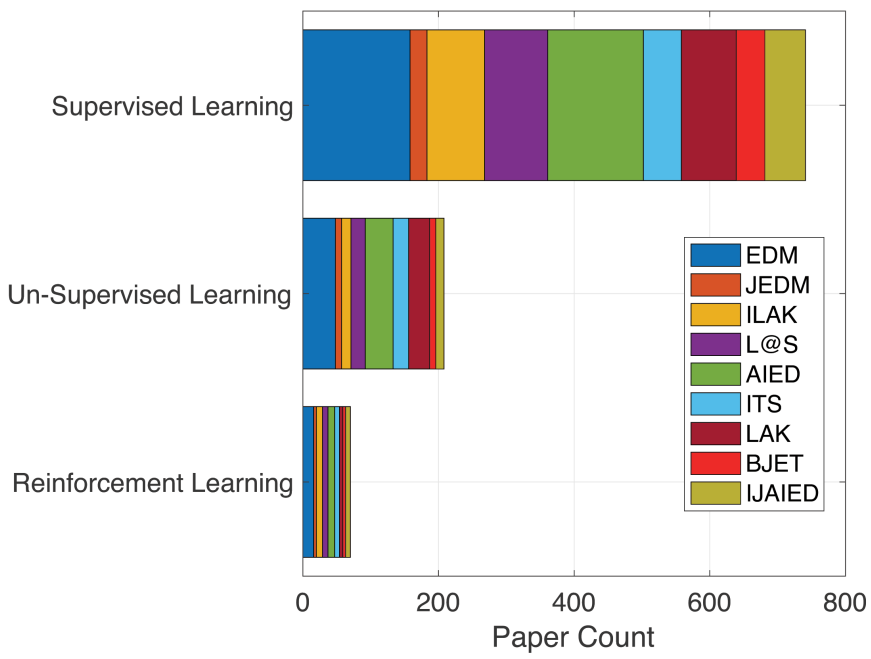

Fig. 8: Statistics of AI papers at different venues and techniques.

\section{Discussion: Insights, Pitfalls, Future Research and Open Issues}

In this section, we provide some key insights from the literature on data-driven $\mathrm{AI}$ in education, limitations of $\mathrm{AI}$ in education, and future research directions and open issues.

\subsection{Insights}

Some key insights from the literature on the use of AI in education discussed in the paper are summarized below. 


\subsubsection{Success of AI in Education}

- Changing Roles of Humans and Machines in Education: Technology advancements in AI might eventually change the roles of teachers substantially with their traditional duties of knowledge dissemination changing to becoming coaches focusing on assessment, mentoring, and monitoring [147]. To this aim, they will need to develop new skills, such as an in-depth understanding of the new education system offered by modern technologies and AI.

- AI is a Learning Catalyst: In terms of AI as a learning catalyst, it is suggested that AI-powered systems will become smarter in their learning and will contribute greatly to the learning process, especially for children. These systems will focus on individual learning requirements tailored to the needs of each student, for example, writing, reading, social or soft skills with fleets of AI-based instructors serving the education needs of future generations without sick leave, maternity leave, or tardiness.

- Teacher and AI Collaboration: The ever-increasing role of AI in education is expected to help in filling the gaps in learning and teaching allowing teachers to perform more efficiently than ever. AI's support of teachers in personalization, evaluation, and testing allows teachers to spend more time on tasks that are beyond machines (AI) and require human capabilities. Leveraging the capabilities of AI-driven technology and teachers is expected to result in better learning and teaching environment [148].

- AI for the Safety of Schools/Classrooms: The recent rise in the shooting accidents in schools and terrorist attacks on educational institutions has resulted in growing safety concerns. According to [149], "school officials need to be able to rapidly evaluate information that could warn of impending school violence and conduct threat assessments prior to a violent outburst in order for strategies to be put in place". In this regard, the outstanding capabilities of data-driven AI algorithms make AI a preferred choice for protective intelligence, which generally involves gathering and assessing information about individuals having the interests, intentions, and capability of launching such attacks, in educational institutes involving a large number of students and staff to be analyzed [150]. To this aim, data from different sources, such as social media posts (images and text), internet search results, public records, and other forums, is collected and fed into AI algorithms to establish links between the individuals' data and potential risks. Threat alerts are then issued to concerned authorities for remedial actions. In the future, AI-based security solutions are expected to go beyond the traditional monitoring and anomaly detection actives, and the focus will shift towards protective intelligence.

- Learning for All: AI is also playing its part in making sure every child gets better learning resources by facilitating students with special needs. For instance, efforts are already made to develop AI-based educational tools for disabled students [151]. Such tools make use of modern technology to develop better and cheaper learning environments and materials, which 
ultimately results in a better and improved learning experience for special children without involving expensive and time-consuming therapy sessions. Moreover, AI-driven machine translation tools are also helping students in bridging the language gap for many second language students. AI is expected to revolutionize special education as well [152].

- Better Analysis of Learners' Feedback: Sentiment analysis allows teachers and administrators to analyze and understand students' feedback and their learning experience in a better way. In distance learning, sentiment analysis could also be proved very effective in several ways. For instance, students' early failure could be predicted by analyzing their feelings, feedback, and learning experience in a course via sentiment analysis, which can ultimately improve the graduation rate by taking necessary remedial actions [153]. Sentiment analysis of students' feedback could also benefit personalized learning tools to further improve/stimulate students' enthusiasm for learning. The role of Sentiment analysis in the education sector is expected to go beyond analyzing students' feedback on a course or a teacher.

- Virtual Facilitators - Robot Teachers: There are many examples of successful implementation of robot teachers including Elias, which is a language teacher at a Finnish school, and Jill Watson, which is a virtual teaching assistant at a US university $[154,155]$. Robot teachers are reliable in their ability to cover the list of topics with perfect consistency. Research has shown that they are not disruptive and can offer positive feedback to human teachers for innovative teaching in the classroom. Some of the challenges associated with using robots as teachers include: short on the specific human touch which includes real and natural reactions to complex human tendencies; lack of creative sense and ability to exert control or enforce discipline in the classroom; the special teacher-pupil bond. Many experts believe machines will be better than humans at most tasks in the future. Reports from Oxford and Yale concluded that AI will outperform humans in several activities soon [156]. However, robots will not be replacing teachers soon because they lack the dynamic, creative ability to inspire students [157]. "In a world where young people are retreating more and more into virtual unreality, the teaching profession has become more important than it ever was. It is human teaching that keeps it real - teaching that keeps young people alive" [158]. As an intermediate stage, AI technology can support human teachers to boost their teaching effectiveness by enabling them to obtain greater insights into student needs and requirements each according to their individual circumstances with minimal human effort overhead. Still, there are known risks associated with moving forward at a pace that is too high in implementing AI solutions for teaching including the loss of the human traits of creativity, diversity, compassion, fun, and out-of-the-box thinking, hence the shortages in quality teaching staff in most developed countries. 


\subsubsection{Limitations of AI in Education/Learning}

There are several aspects of education where AI alone can not contribute much. The limitations and pitfalls of AI in education can be mainly divided in terms of technological and social aspects. The technological pitfalls of AI in education are either due to conceptual/algorithmic limitations or because of the training data. Some of the pitfalls are listed below.

- Failure in the Extraction of Interpretable and Actionable Insights: AI alone is not enough to fully understand and extract interpretable and actionable insights from the educational data to improve students' learning. For instance, in [159], several case studies have been reported where simply AI-based predictions are not enough to understand and improve the learning process. The authors, rather propose an explanatory learning model by employing Human-Computer Interaction (HCI) and AI (i.e., model interpretation approaches at the interpretation stage [160]) techniques to derive insights from the students' learning experiences and suggest how the technology could be made more useful for the learners.

- Failure in Generation of Course Content: All AI techniques can do is to recommend a particular chapter/course content to a student at a timestamp (i.e., alter the sequence of the course materials). According to Popovic [161], presenting the same material in a different sequence has little impact on the learner's performances, and the real game-changer is the generation of course content on the fly, which is a very challenging task.

- Lack of Clarity and Flexibility in Teaching of Virtual Teachers (Robots): Though content and learning analytics contributed to a greater extent in the creation of personalized content; however, there are concerns about the clarity and flexibility in teaching or the way content is delivered by virtual (robots) tutors/teaching assistants. Moreover, teachers motivate students to learn and master a course. However, robots lack such capabilities.

- Lack of Training Data: The strength of AI techniques comes from training data, which has a significant impact on their prediction capabilities. However, it is very challenging to acquire a sufficient amount of training samples for AI algorithms in a sensitive and high-stakes environment, such as the education sector, where one can't afford any risk with students [161].

- High Risk due to Biased Data: AI algorithms need precise and sound data to be more effective. According to Calhoun Williams [161], a high risk of biases is involved with $\mathrm{AI}$ in education, where it is very much probable to reach false conclusions due to inaccurate predictions.

- Testing and Evaluation of AI-systems: Education is one of the critical applications where several risks are associated with the deployment of AI-based solutions. In order to develop, users' trust in AI systems in education, the solutions need to be properly formulated, trained and evaluated on representative and real-world data before deployment, which is a challenging process.

- Security Concerns: The increasing dependence on AI will also lead to serious privacy concerns [162]. The institutions would need to focus not only 
on quality but also on data privacy. According to Calhoun Williams [161], in schools data need to be carefully handled and the administrations need to be ready for AI from a policy standpoint.

There are also some drawbacks of AI in education that are not directly linked with the limitations of the AI algorithms rather their negative impact on society. For instance, deploying AI at school level may result in kids' addiction to technology, such as phones and tablets, which may harm their health and personalities. The use of technology in learning also limits interaction with fellows and teachers which may result in isolation. Similarly, deployment of AI in education will increase dependence on expensive technology, which may also result in more consumption of power which will ultimately increase schools' budgets. Such expenses might deprive the poor of quality education. AI in education may also result in joblessness. It is evident from the above discussion that several factors need to be considered while deploying AI in education. Moreover, it is also very important to define the aspects, processes, and levels at which AI could be deployed in the education sector.

\subsection{Future Research Directions and Open Issues}

In this section, we provide some potential directions for future research in the domain. We classify the open directions of research on AI in education into four main areas:

\subsubsection{Teaching Methods and Pedagogy}

- Customized Teaching Pedagogy: Pedagogical Models represent the methods practiced by an effective teacher to better engage the students in a challenging learning environment. AI-based solutions have been proved very effective in the domain allowing educators to develop effective pedagogical models, strategies, and methods to support individuals through data analytics. The literature reports several interesting AI-based solutions to identify teaching pedagogy better suited for individuals. For instance, Xiao et al. [163] employed AI techniques to assess and identify effective pedagogical factors leading to a better learning practice for primary school students. However, research is still needed to identify the best teaching pedagogy that suits each learner skills and interests. A customized teaching pedagogy which offers effective adjustments could help students in grasping new concepts and course materials effectively [164].

- Technology Integration in Classroom: In most cases, technology products (hardware/software) are brought into classrooms using a trial-and-error model. Teachers are asked to integrate technology into curricula and learners are asked to use technology in learning almost all subjects. Developing a model for effective technology integration is critical and challenging due to many reasons. Technology products, learners' skills and interests, and knowledge areas are very diverse. Also, researchers usually focus on 
the benefits of integrating technology in classrooms and the best ways to achieve the most integration [165]. However, it is intuitive to say that there are possible and sometimes clear negative impacts that can't be ignored when it comes to technology integration [166]. This makes the development of an effective AI model for technology integration a challenging task that requires attention by researchers.

Moreover, the integration of NLP and AI techniques in classrooms may explore a new perspective of learning and teaching, leading to more effective measures of teaching practices. There are already some efforts in this direction [167]. However, analyzing and extracting linguistic features/information of classroom discourse for automatic feedback to teachers is a challenging task and needs to be further explored.

- Personalized Tutoring: How to provide personalized tutoring and real-time feedback beyond math topics for diverse levels of learners? A good example is Carnegie Learning's "Mika" software for MathiaU which is designed to deliver a better math learning experience to every developmental Math student [168]. This includes the need to design personalized AI-based tutoring robots [169].

\subsubsection{Supporting Educator Effectiveness}

- Minimizing Biased Evaluation: One of the main challenges that each educator's face is how to minimize personal biases when it comes to grading and evaluation. This stems from the fact that human behaviors are hard to predict when it comes to relationships and judgment [170]. Relying on AI can reasonably help in protecting against internal biases by offering an insight into student's performance based on data. However, designing AI techniques that can help in minimizing biased evaluation while keeping teacher's attitudes in mind is not easy and requires careful considerations. Moreover, the majority of the attempts in the literature relied on the traditional black-box models, which do not provide any explanation of their outcome/prediction. In a critical application like education, such black-box models are not adequate [171]. Explainable AI for education is one of the potential future research directions in the domain.

- Identifying Students at Risk: Detecting alarming patterns and potential risk of students to drop out is an important area where AI can play a key role.

- Scheduling Efficiency: Optimal learning is connected to optimal scheduling of learning lessons and activities [172]. Knowing the best way to design optimal teaching schedules is challenging due to the contributing factors such as understanding how people learn (cognitive psychology, knowledge retention, etc.), topic, age, level of a learner, availability of qualified teachers, availability of resources such as physical space, etc. AI modeling for optimized and adaptive teaching policies when it comes to effective scheduling is an area of research. In [173], authors proposed online job scheduling using 
AI. Such efforts can help in understanding the need for effective scheduling of learning lessons.

- Protective Intelligence to Secure Schools: Keeping in view the rise of shooting accidents in schools, and as also recommended in [149], schools' administration need to regularly analyze, evaluate students' information for potential treats, AI-based protective intelligence is one of the potential future research directions to ensure schools' safety.

- Visual Sentiment Analysis: Visual sentiment analysis could be very useful in various ways [174]. For instance, they could help to automatically filter and summarize visual educational contents. It could also help to perceive and stimulate students' interest in both traditional and on-screen teaching/e-learning [175].

\subsubsection{Improving Education Systems}

- Predicting Student's Future: Developing AI solutions to predict the best career paths and specialization areas are challenging due to the diversity of students backgrounds, skills, biological differences, environmental aspects, needs, etc. A comprehensive AI software application is needed to intelligently predict a student's future and the most suitable career path selection. The study in [176] highlights a study that shows the power of AI in predicting employment at graduation.

- Mistakes Implications: In education, the consequences of making mistakes can be serious. When AI is used in making decisions, it is critical to identify the potential consequences and risks at different levels. If the AI algorithm recommends the wrong reading or inappropriate clip to students, it can lead to serious social or economic issues. Therefore, AI in education researchers need to integrate a risk factor to quantify potential mistakes and errors implications of implementing any AI technique in education.

- Generation of Course Contents on the Fly: AI techniques have been proved very effective in course content recommendations. However, it will be very interesting to investigate how AI can be employed in content generation for a particular learner, which will be a real game-changer in the education sector [161].

- Favoring AI over Traditional Statistical Methods: Research is still needed to identify when AI is better than traditional statistical methods when it comes to deciding on education at different levels. Over the years, the usage of traditional statistical analytical methods has been successful (at least this is what we observed). Nevertheless, it is vital to study if AI analytics can be more successful in deciding on improving our education.

- Explanatory Learning Model: To obtain more interpret-able and actionable insights from educational data, explanatory learning models involving all the stack-holders including learners' parents and schools, etc., need to be developed [159]. AI along with Human-Computer Interaction (HCI) methods can then be jointly utilized to better analyze the data. 


\subsubsection{AI Issues and Concerns}

- Identifying Ethical and Privacy Issues: While AI can offer promising solutions in many fields including education, many ethical considerations can arise and cause limitations. Developing AI algorithms for education with ethical considerations in mind is challenging due primarily to the different definitions of what's and what isn't ethical in education. Also, it is critical to prevent using AI is leading to serious biases when it comes to analyzing data and identifying patterns. In the area of privacy, when our data are left to machines to analyze and detect patterns, this is by itself can lead to serious privacy implications. For example, having access to students' online search behaviors can lead to detecting personal issues which can negatively lead to long term impacts. Therefore, AI researchers need to look for ways to tame their algorithms and analytics when it comes to analyzing data and detecting patterns. There are already some efforts in this direction [177]. For instance, author of [178] discusses ways to address the ethical issues of using AI.

- Security Implications: AI is very dependent on data. Data in the education field are miscellaneous. Designing AI algorithms while security is very prominent and in mind is critical. This requires distinguishing between sensitive and insensitive data before jumping to apply AI techniques on educational data. Hence, researchers are in need to develop intelligent AI techniques that are ready to deal with data in classified and careful ways.

\section{Conclusions}

In this paper, we have reviewed applications of data-driven AI in the education sector from different perspectives. On the one side, we provided a detailed overview of the existing tools and applications developed as a result of the efforts of the AI community in education. On the other hand, we highlighted the research trends in the domain over the last seven years as well as the current limitations and pitfalls of data-driven AI in education. In particular, we provided a detailed overview of the existing literature in eight application domains, such as students' grading and evaluation, students' dropout, sentiment analysis, intelligent tutoring systems, and classroom monitoring. The efforts made in these applications resulted in several interesting tools helping students and administration in several ways. The survey also highlighted key market players, tools, and platforms in the above-mentioned applications of AI in education, which are expected to provide a good starting point for beginners in the domain. We also provided an overview of the most commonly used data-driven AI strategies and techniques in different applications of AI in education. In addition, a detailed bibliometric analysis has been provided to highlight the research trends of $\mathrm{AI}$ in the education sector over the last few years. The bibliometric analysis shows a significant contribution from researcher USA. Moreover, students' grading and evaluation has been among 
the mostly explored application discussed in the paper. Based on our analysis of the existing literature and experience in the domain, we also identified the current limitations and the pitfalls of data-driven AI in education. We believe such a detailed analysis of the domain will provide a baseline for future research in the domain.

Acknowledgements The authors would like to extend their gratitude to Dr. Sebastian Ventura for the time and effort spent on reviewing and feedback on our manuscript. Indeed, his feedback contributed a lot in improving the quality of the work.

\section{References}

1. T. E. D. Mining, "Enhancing teaching and learning through educational data mining and learning analytics: An issue brief," in Proceedings of conference on advanced technology for education, 2012.

2. "Research and markets: Artificial intelligence market in the us education sector 20182022," https://www.solaresearch.org/, accessed: 2019-12-30.

3. M. Mitchell, Artificial Intelligence: A Guide for Thinking Humans. Penguin UK, 2019.

4. P. Domingos, The master algorithm: How the quest for the ultimate learning machine will remake our world. Basic Books, 2015.

5. "Gthe use of artificial intelligence (ai) in education," https://tinyurl.com/y44hym7y, accessed: 2020-04-13.

6. A. K. Goel and D. A. Joyner, "Design of an online course on knowledge-based ai." in AAAI, 2016, pp. 4089-4094.

7. "Artificial intelligence in education: where are we now?" https://www.youtube.com/ watch?v=54-yKBv6xeU, accessed: 2020-12-1.

8. B. du Boulay, "Artificial intelligence as an effective classroom assistant," IEEE Intelligent Systems, vol. 31, no. 6, pp. 76-81, 2016.

9. K. Holstein, "Towards teacher-ai hybrid systems," in Companion Proceedings of the Eigth International Conference on Learning Analytics $\&$ Knowledge, 2018.

10. "How artificial intelligence is being used in the classroom," https://tinyurl.com/ yy2oomye, accessed: 2020-04-13.

11. C. Romero and S. Ventura, "Educational data mining: a review of the state of the art," IEEE Transactions on Systems, Man, and Cybernetics, Part C (Applications and Reviews), vol. 40, no. 6, pp. 601-618, 2010.

12. - "Educational data mining and learning analytics: An updated survey," Wiley Interdisciplinary Reviews: Data Mining and Knowledge Discovery, vol. 10, no. 3, p. e1355, 2020.

13. R. Ferreira-Mello, M. André, A. Pinheiro, E. Costa, and C. Romero, "Text mining in education," Wiley Interdisciplinary Reviews: Data Mining and Knowledge Discovery, vol. 9, no. 6, p. e1332, 2019.

14. "Educationl data mining," http://educationaldatamining.org/, accessed: 2019-12-30.

15. "Solar: Society for learning analytics research," https://www.solaresearch.org/, accessed: 2019-12-30.

16. G.-J. Hwang and Y.-F. Tu, "Roles and research trends of artificial intelligence in mathematics education: A bibliometric mapping analysis and systematic review," Mathematics, vol. 9, no. 6, p. 584, 2021.

17. C. Romero and S. Ventura, "Educational data mining: A survey from 1995 to 2005," Expert systems with applications, vol. 33, no. 1, pp. 135-146, 2007.

18. R. S. Baker and K. Yacef, "The state of educational data mining in 2009: A review and future visions," JEDM- Journal of Educational Data Mining, vol. 1, no. 1, pp. 3-17, 2009 
19. C. Fischera, Z. A. Pardosb, R. S. Bakerc, J. J. Williamsd, P. Smythe, R. Yue, S. Slaterc, R. Bakere, and M. Warschauere, "Mining big data in education: Affordances and challenges."

20. N. Mduma, K. Kalegele, and D. Machuve, "A survey of machine learning approaches and techniques for student dropout prediction," 2019

21. A. Almasri, A. Ahmed, N. Almasri, Y. S. Abu Sultan, A. Y. Mahmoud, I. S. Zaqout, A. N. Akkila, and S. S. Abu-Naser, "Intelligent tutoring systems survey for the period 2000-2018," 2019

22. F. Tahiru, "Ai in education: A systematic literature review," Journal of Cases on Information Technology (JCIT), vol. 23, no. 1, pp. 1-20, 2021.

23. M. Al-Emran, S. I. Malik, and M. N. Al-Kabi, "A survey of internet of things (IoT) in education: Opportunities and challenges," in Toward Social Internet of Things (SIoT): Enabling Technologies, Architectures and Applications. Springer, 2020, pp. 197-209.

24. O. Zawacki-Richter, V. I. Marín, M. Bond, and F. Gouverneur, "Systematic review of research on artificial intelligence applications in higher education-where are the educators?" International Journal of Educational Technology in Higher Education, vol. 16, no. 1, pp. 1-27, 2019.

25. B. Flanagan and H. Ogata, "Learning analytics platform in higher education in japan," Knowledge Management \& E-Learning: An International Journal, vol. 10, no. 4, pp. 469-484, 2018.

26. I. E. Livieris, K. Drakopoulou, V. T. Tampakas, T. A. Mikropoulos, and P. Pintelas, "Predicting secondary school students' performance utilizing a semi-supervised learning approach," Journal of educational computing research, vol. 57, no. 2, pp. 448-470, 2019 .

27. M. Hussain, W. Zhu, W. Zhang, S. M. R. Abidi, and S. Ali, "Using machine learning to predict student difficulties from learning session data," Artificial Intelligence Review, vol. 52, no. 1, pp. 381-407, 2019

28. C. Masci, G. Johnes, and T. Agasisti, "Student and school performance across countries: A machine learning approach," European Journal of Operational Research, vol. 269, no. 3, pp. 1072-1085, 2018.

29. "Pearson's WriteToLearn," https://www.pearson.com/country-selector.html, accessed: 2020-04-13.

30. "Quantum adaptive learning," https://www.quantumal.com/, accessed: 2020-04-13.

31. "Azure for education," https://azure.microsoft.com/en-us/education/, accessed: 2020 04-13.

32. "Hubert.ai," https://hubert.ai/, accessed: 2020-04-13.

33. "Lightside labs," https://tinyurl.com/yadrjze6, accessed: 2020-02-06.

34. "Proctorio," https://tinyurl.com/yxy9e74q, accessed: 2020-04-13.

35. "GradeScope: A grading tool," https://www.gradescope.com/, accessed: 2020-02-06.

36. "Respondus: An assessment tool for learning systems," https://web.respondus.com/, accessed: 2020-02-06.

37. L. Aulck, N. Velagapudi, J. Blumenstock, and J. West, "Predicting student dropout in higher education," arXiv preprint arXiv:1606.06364, 2016.

38. N.-S. Chen, I.-L. Cheng, S. W. Chew et al., "Evolution is not enough: Revolutionizing current learning environments to smart learning environments," International Journal of Artificial Intelligence in Education, vol. 26, no. 2, pp. 561-581, 2016.

39. M. Solis, T. Moreira, R. Gonzalez, T. Fernandez, and M. Hernandez, "Perspectives to predict dropout in university students with machine learning," in 2018 IEEE International Work Conference on Bioinspired Intelligence (IWOBI). IEEE, 2018, pp. $1-6$.

40. A. Pilkington, P. Bowen, R. C. Rose, D. R. Rajasinghe, and I. Evans, "A qualitative study of student retention: The university javascript: void (0); academic's perspective," International Journal of Academic Multidisciplinary Research, vol. 2, no. 10, pp. 19$28,2018$.

41. V. Tinto, Leaving college: Rethinking the causes and cures of student attrition. ERIC, 1987

42. S. Liu, W. Cui, Y. Wu, and M. Liu, "A survey on information visualization: recent advances and challenges," The Visual Computer, vol. 30, no. 12, pp. 1373-1393, 2014. 
43. C. Taylor, K. Veeramachaneni, and U.-M. O'Reilly, "Likely to stop? predicting stopout in massive open online courses," arXiv preprint arXiv:1408.3382, 2014.

44. "Campuslabs: Data driven innovations," https://www.campuslabs.com/ campus-labs-platform/retention-and-success/, accessed: 2020-02-06.

45. "RNL student retention predictor," https://tinyurl.com/voh3cjk, accessed: 2020-02-06.

46. "Nuro retention," https://www.campuslabs.com/campus-labs-platform/ retention-and-success/, accessed: 2020-02-06.

47. "Othot: Retention analytics," https://othot.com/retention-analytics/, accessed: 202002-06.

48. "Campusnexus succeed: Retention analytics," https://www.campusmanagement.com/ products/student-retention-software/, accessed: 2020-02-06.

49. H. Al-Samarraie, A. Shamsuddin, and A. I. Alzahrani, "A flipped classroom model in higher education: a review of the evidence across disciplines," Educational Technology Research and Development, pp. 1-35, 2019.

50. J. S. Twyman, "Competency-based education: Supporting personalized learning. connect: Making learning personal." Center on Innovations in Learning, Temple University, 2014.

51. E. Van Melle, J. R. Frank, E. S. Holmboe, D. Dagnone, D. Stockley, J. Sherbino, I. C. based Medical Education Collaborators et al., "A core components framework for evaluating implementation of competency-based medical education programs," Academic Medicine, vol. 94, no. 7, pp. 1002-1009, 2019.

52. D. Shawky and A. Badawi, "Towards a personalized learning experience using reinforcement learning," in Machine learning paradigms: Theory and application. Springer, 2019, pp. 169-187.

53. Y. El Miedany, "Flipped learning," in Rheumatology Teaching. Springer, 2019, pp. 285-303.

54. M. L. Sein-Echaluce, Á. Fidalgo-Blanco, and F. J. García-Peñalvo, Innovative Trends in Flipped Teaching and Adaptive Learning. IGI Global, 2019.

55. N. Ahmad Uzir, D. Gašević, W. Matcha, J. Jovanović, and A. Pardo, "Analytics of time management strategies in a flipped classroom," Journal of Computer Assisted Learning, vol. 36, no. 1, pp. 70-88, 2020.

56. A. Pardo, K. Bartimote, S. B. Shum, S. Dawson, J. Gao, D. Gašević, S. Leichtweis, D. Liu, R. Martínez-Maldonado, N. Mirriahi et al., "Ontask: Delivering data-informed, personalized learning support actions," Journal of Learning Analytics, vol. 5, no. 3, pp. 235-249, 2018.

57. "Third space learning," https://thirdspacelearning.com, accessed: 2020-04-13.

58. "Knewton," https://www.knewton.com/, accessed: 2020-04-13

59. "Enlearn," https://www.enlearn.org/, accessed: 2020-04-13.

60. "Watson incorporation," www.ibm.com/watson/education, accessed: 2019-11-13.

61. "Querium: The home master," http://querium.com/, accessed: 2020-04-13.

62. "Online learning is our business - let us do it for you," https://edly.io, accessed: 202004-13.

63. "Squirrel AI learning," https://squirrelai.com/our-story/, accessed: 2020-04-13.

64. "Mobymax: Fix learning gaps," https://www.mobymax.com/, accessed: 2020-04-13.

65. "Kidaptive's adaptive learning platform," https://builtin.com/artificial-intelligence/ ai-in-education, accessed: 2020-04-26.

66. "Century tech: Supercharge your teaching," https://www.century.tech, accessed: 202004-26.

67. O. W. Adejo and T. Connolly, "Predicting student academic performance using multimodel heterogeneous ensemble approach," Journal of Applied Research in Higher Education, vol. 10 , no. 1 , pp. $61-75,2018$

68. I. Khan, A. Al Sadiri, A. R. Ahmad, and N. Jabeur, "Tracking student performance in introductory programming by means of machine learning," in 20194 th MEC International Conference on Big Data and Smart City (ICBDSC). IEEE, 2019, pp. $1-6$.

69. B.-H. Kim, E. Vizitei, and V. Ganapathi, "Gritnet: Student performance prediction with deep learning," arXiv preprint arXiv:1804.07405, 2018. 
70. N. T. P. Giang, T. T. Dien, and T. T. M. Khoa, "Sentiment analysis for university students' feedback," in Future of Information and Communication Conference. Springer, 2020 , pp. 55-66.

71. Z. Kastrati, A. S. Imran, and A. Kurti, "Weakly supervised framework for aspectbased sentiment analysis on students' reviews of moocs," IEEE Access, vol. 8, pp. 106 799-106 810, 2020.

72. Z. Liu, C. Yang, S. Rüdian, S. Liu, L. Zhao, and T. Wang, "Temporal emotion-aspect modeling for discovering what students are concerned about in online course forums," Interactive Learning Environments, pp. 1-30, 2019.

73. K. Ravi and V. Ravi, "A survey on opinion mining and sentiment analysis: tasks, approaches and applications," Knowledge-Based Systems, vol. 89, pp. 14-46, 2015.

74. M. Munezero, C. S. Montero, M. Mozgovoy, and E. Sutinen, "Exploiting sentiment analysis to track emotions in students' learning diaries," in Proceedings of the 13th Koli Calling International Conference on Computing Education Research, 2013, pp. $145-152$.

75. Z. Kechaou, M. B. Ammar, and A. M. Alimi, "Improving e-learning with sentiment analysis of users' opinions," in 2011 IEEE global engineering education conference (EDUCON). IEEE, 2011, pp. 1032-1038.

76. L. Mostafa, "Student sentiment analysis using gamification for education context," in International Conference on Advanced Intelligent Systems and Informatics. Springer, 2019, pp. 329-339.

77. "Softbank robotics," https://www.softbankrobotics.com/emea/en/, accessed: 2020-0413.

78. "Softbank's NAO," https://www.softbankrobotics.com/emea/en/nao, accessed: 202004-13.

79. "Nao in education," https://tinyurl.com/vuhyl9h, accessed: 2020-04-13.

80. "IRONSIDE: Predict higher education student retention risk," https://www. bpuholdings.com/services/zimgo/, accessed: 2020-02-06.

81. "Talkwalker: Understand trends and react to customer opinions instantly," https:// tinyurl.com/voqwqqp, accessed: 2020-02-06.

82. "Moodle: A learning management system," https://moodle.org/, accessed: 2020-04-13

83. W. Ma, O. O. Adesope, J. C. Nesbit, and Q. Liu, "Intelligent tutoring systems and learning outcomes: A meta-analysis." Journal of educational psychology, vol. 106, no. 4, p. 901,2014

84. F. Yang and F. W. Li, "Study on student performance estimation, student progress analysis, and student potential prediction based on data mining," Computers \& Education, vol. 123, pp. 97-108, 2018.

85. A. Elhassan, I. Jenhani, and G. B. Brahim, "Remedial actions recommendation via multi-label classification: A course learning improvement method," International Journal of Machine Learning and Computing, vol. 8, no. 6, 2018.

86. "Qbot: Help students to reach their ful potential," https://tinyurl.com/wwvyrkf, accessed: 2020-02-06.

87. "myedmatch," http://www.myedmatch.com, accessed: 2020-04-13.

88. "Teachermatch," https://tinyurl.com/whrjl64, accessed: 2020-04-13

89. F. Paci, D. Brunelli, and L. Benini, " $0,1,2$, many - a classroom occupancy monitoring system for smart public buildings," in Proceedings of the 2014 Conference on Design and Architectures for Signal and Image Processing. IEEE, 2014, pp. 1-6.

90. Y. P. Raykov, E. Ozer, G. Dasika, A. Boukouvalas, and M. A. Little, "Predicting room occupancy with a single passive infrared (PIR) sensor through behavior extraction," in Proceedings of the 2016 ACM International Joint Conference on Pervasive and Ubiquitous Computing. ACM, 2016, pp. 1016-1027.

91. T. Sutjarittham, H. H. Gharakheili, S. S. Kanhere, and V. Sivaraman, "Data-driven monitoring and optimization of classroom usage in a smart campus," in 2018 17th ACM/IEEE International Conference on Information Processing in Sensor Networks (IPSN). IEEE, 2018, pp. 224-229.

92. S. K. Howard, J. Yang, J. Ma, C. Ritz, J. Zhao, and K. Wynne, "Using data mining and machine learning approaches to observe technology-enhanced learning," in 2018 IEEE International Conference on Teaching, Assessment, and Learning for Engineering (TALE). IEEE, 2018, pp. 788-793. 
93. V. Soloviev, "Machine learning approach for student engagement automatic recognition from facial expressions," Scientific Publications of the State University of Novi Pazar Series A: Applied Mathematics, Informatics and mechanics, vol. 10, no. 2, pp. 79-86, 2018.

94. Y. H. V. Chua, J. Dauwels, and S. C. Tan, "Technologies for automated analysis of co-located, real-life, physical learning spaces: Where are we now?" in Proceedings of the 9th International Conference on Learning Analytics $\&$ Knowledge. ACM, 2019, pp. 11-20.

95. "Jibble: An error-free attendance app with biometric verification," https://www.jibble. io/, accessed: 2020-02-06.

96. "Looplearn: Automated attendance keeping," https://www.looplearn.net, accessed: 2020-02-06.

97. "Safr for security provides accurate real-time face recognition," https://news. milestonesys.com/safr-for-security-provides-accurate-real-time-face-recognition/, accessed: 2020-04-13.

98. "Airclass," https://info.airclass.com/goodbye, accessed: 2020-04-13.

99. "Captemo: An emotion recognition platform," https://www.captemo.com, accessed: 2020-02-06.

100. "Blippar: Transform the classroom experience," https://www.blippar.com/build-ar/ augmented-reality-education, accessed: 2020-04-26.

101. N. Bosch, S. K. D’Mello, R. S. Baker, J. Ocumpaugh, V. Shute, M. Ventura, L. Wang, and W. Zhao, "Detecting student emotions in computer-enabled classrooms," in IJCAI, 2016, pp. 4125-4129.

102. M. Mavrikis, "Modelling student interactions in intelligent learning environments: constructing Bayesian networks from data," International Journal on Artificial Intelligence Tools, vol. 19, no. 06, pp. 733-753, 2010.

103. R. S. Baker, J. Clarke-Midura, and J. Ocumpaugh, "Towards general models of effective science inquiry in virtual performance assessments," Journal of Computer Assisted Learning, vol. 32, no. 3, pp. 267-280, 2016.

104. L. Fratamico, C. Conati, S. Kardan, and I. Roll, "Applying a framework for student modeling in exploratory learning environments: Comparing data representation granularity to handle environment complexity," International Journal of Artificial Intelligence in Education, vol. 27, no. 2, pp. 320-352, 2017.

105. V. Kostakos and M. Musolesi, "Avoiding pitfalls when using machine learning in HCI studies," interactions, vol. 24, no. 4, pp. 34-37, 2017.

106. C. Conati, K. Porayska-Pomsta, and M. Mavrikis, "AI in education needs interpretable machine learning: Lessons from open learner modelling," arXiv preprint arXiv:1807.00154, 2018.

107. C. Newton, "Can AI fix education? we asked Bill Gates," The Verge, 2016.

108. H. Hutchinson, "A quick look at 2019 trends in higher education for early career academics."

109. B. Woolf, "Web-based learning environments. building intelligent interactive tutors," 2009.

110. Y. Zhou and M. W. Evens, "A practical student model in an intelligent tutoring system," in Proceedings 11th international conference on tools with artificial intelligence. IEEE, 1999, pp. 13-18.

111. S. Katz, P. Albacete, I.-A. Chounta, P. Jordan, B. M. McLaren, and D. Zapata-Rivera, "Linking dialogue with student modelling to create an adaptive tutoring system for conceptual physics," International Journal of Artificial Intelligence in Education, pp. 1-49, 2021.

112. "Dreambox learning," https://www.dreambox.com/, accessed: 2020-04-13.

113. "Carnegie learning," www.carnegielearning.com, accessed: 2020-04-13.

114. "St math," https://web.stmath.com/, accessed: 2020-04-13.

115. "Assistments: Assign online," https://new.assistments.org, accessed: 2020-04-13.

116. "Cognizant," https://www.cognizant.com/education-technology-solutions, accessed: 2020-04-13.

117. "Taxonomy of machine learning algorithms," https://tinyurl.com/w68oagu, accessed: 2020-04-13. 
118. E. A. Majeed and K. N. Junejo, "Grade prediction using supervised machine learning techniques," e-Proceedings of the 4th Global Summit on Education, 2016.

119. M. Nagy and R. Molontay, "Predicting dropout in higher education based on secondary school performance," in 2018 IEEE 22nd International Conference on Intelligent Engineering Systems (INES). IEEE, 2018, pp. $000389-000394$.

120. Z. Iqbal, A. Qayyum, S. Latif, and J. Qadir, "Early student grade prediction: An empirical study," in 2019 2nd International Conference on Advancements in Computational Sciences (ICACS). IEEE, 2019, pp. 1-7.

121. H. Aldowah, H. Al-Samarraie, and W. M. Fauzy, "Educational data mining and learning analytics for 21st century higher education: A review and synthesis," Telematics and Informatics, 2019.

122. M. Durairaj and C. Vijitha, "Educational data mining for prediction of student performance using clustering algorithms," International Journal of Computer Science and Information Technologies, vol. 5, no. 4, pp. 5987-5991, 2014

123. G. Akçapỳnar, A. Altun, and E. Cosgun, "Investigating students' interaction profile in an online learning environment with clustering," in 2014 IEEE 14th International Conference on Advanced Learning Technologies. IEEE, 2014, pp. 109-111.

124. S. Dwivedi and V. K. Roshni, "Recommender system for big data in education," in 2017 5th National Conference on E-Learning \& E-Learning Technologies (ELELTECH). IEEE, 2017, pp. 1-4.

125. F. Siraj and M. A. Abdoulha, "Uncovering hidden information within university's student enrollment data using data mining," in 2009 Third Asia International Conference on Modelling \&s Simulation. IEEE, 2009, pp. 413-418.

126. C. Romero, S. Ventura, and E. García, "Data mining in course management systems: Moodle case study and tutorial," Computers $E S$ Education, vol. 51, no. 1, pp. 368-384, 2008 .

127. M. A. Hogo, "Evaluation of e-learners behaviour using different fuzzy clustering models: a comparative study," arXiv preprint arXiv:1003.1499, 2010

128. V. R. P. Borges, S. Esteves, P. de Nardi Araújo, L. C. de Oliveira, and M. Holanda, "Using principal component analysis to support students' performance prediction and data analysis," in Brazilian Symposium on Computers in Education (Simpósio Brasileiro de Informática na Educação-SBIE), vol. 29, no. 1, 2018, p. 1383.

129. D. Gkatzia, H. Hastie, S. Janarthanam, and O. Lemon, "Generating student feedback from time-series data using reinforcement learning," in Proceedings of the 14th European Workshop on Natural Language Generation, 2013, pp. 115-124.

130. F. A. Dorça, L. V. Lima, M. A. Fernandes, and C. R. Lopes, "Comparing strategies for modeling students learning styles through reinforcement learning in adaptive and intelligent educational systems: An experimental analysis," Expert Systems with Applications, vol. 40, no. 6, pp. 2092-2101, 2013.

131. P. Wang, J. P. Rowe, W. Min, B. W. Mott, and J. C. Lester, "Interactive narrative personalization with deep reinforcement learning." in IJCAI, 2017, pp. 3852-3858

132. G. Fenza, F. Orciuoli, and D. G. Sampson, "Building adaptive tutoring model using artificial neural networks and reinforcement learning," in 2017 IEEE 17th international conference on advanced learning technologies (ICALT). IEEE, 2017, pp. 460-462.

133. J. P. Rowe and J. C. Lester, "Improving student problem solving in narrative-centered learning environments: A modular reinforcement learning framework," in International Conference on Artificial Intelligence in Education. Springer, 2015, pp. 419-428.

134. O. Ellegaard and J. A. Wallin, "The bibliometric analysis of scholarly production: How great is the impact?" Scientometrics, vol. 105, no. 3, pp. 1809-1831, 2015.

135. "JEDM: Journal of Educational Data Mining," https://jedm.educationaldatamining. org/index.php/JEDM, accessed: 2020-11-11.

136. "Learning at scale," https://learningatscale.acm.org/las2020/, accessed: 2020-11-11

137. "International Learning Analytics and Knowledge Conference," https://www. solaresearch.org/conference-proceedings/, accessed: 2019-12-21.

138. "International Conference on Artificial Intelligence in Education," https://link. springer.com/conference/aied, accessed: 2020-11-11.

139. "International Conference on Intelligent Tutoring Systems," https://link.springer. com/conference/its, accessed: 2020-11-11. 
140. "Journal of Learning Analytics," https://www.solaresearch.org/journal/, accessed: 2020-11-11.

141. "British Journal of Educational Technology," https://onlinelibrary.wiley.com/journal/ 14678535, accessed: 2020-11-11.

142. "International Journal on Artificial Intelligence in Education," https://www.springer. com/journal/40593/, accessed: 2020-11-11.

143. "ACM Digital Library," https://dl.acm.org/, accessed: 2020-11-11.

144. "SCOPUS," https://www.scopus.com, accessed: 2020-11-11.

145. "Cross ref," https://www.crossref.org, accessed: 2020-04-16.

146. "Harzing's publish or perish' utility," https://harzing.com/resources/ publish-or-perish, accessed: 2019-12-21.

147. "DZone: Will AI replace teachers?" https://tinyurl.com/yxyl6lft, accessed: 2019-12-18.

148. "How is ai used in education - real world examples of today and a peek into the future," https://bernardmarr.com/default.asp?contentID=1541, accessed: 2020-10-13.

149. B. DeVos, K. M. Nielsen, A. M. Azar et al., "Final report of the federal commission on school safety. presented to the president of the united states." US Department of Education, 2018

150. "Edtechchris: Can ai and protective intelligence help keep our schools safe?" https: //tinyurl.com/yycblezr, accessed: 2020-10-13.

151. A. S. Drigas and R.-E. Ioannidou, "Artificial intelligence in special education: A decade review," International Journal of Engineering Education, vol. 28, no. 6, p. 1366, 2012.

152. "Ai has already started reshaping special education," https://tinyurl.com/y36ffu6t, accessed: 2020-10-13.

153. L.-C. Yu, C.-W. Lee, H. Pan, C.-Y. Chou, P.-Y. Chao, Z. Chen, S. Tseng, C. Chan, and K. R. Lai, "Improving early prediction of academic failure using sentiment analysis on self-evaluated comments," Journal of Computer Assisted Learning, vol. 34, no. 4, pp. 358-365, 2018 .

154. "Techno teachers: Finnish school trials robot educators," https://tinyurl.com/uln85x7, accessed: 2020-04-13.

155. A. K. Goel and L. Polepeddi, "Jill watson: A virtual teaching assistant for online education," Georgia Institute of Technology, Tech. Rep., 2016.

156. P. R. Spence, A. Edwards, and C. Edwards, "Attitudes, prior interaction, and petitioner credibility predict support for considering the rights of robots," in Companion of the 2018 ACM/IEEE International Conference on Human-Robot Interaction. ACM, 2018, pp. 243-244.

157. M. G. Voskoglou and A.-B. M. Salem, "Benefits and limitations of the artificial with respect to the traditional learning of mathematics," Mathematics, vol. 8, no. 4, p. 611, 2020 .

158. A. Singh, "Human teaching verses robotic teaching," Journal of Management Science, Operations 8 Strategies (e ISSN 2456-9305), vol. 2, no. 3, pp. 34-38, 2019.

159. C. P. Rosé, E. A. McLaughlin, R. Liu, and K. R. Koedinger, "Explanatory learner models: Why machine learning (alone) is not the answer," British Journal of Educational Technology, 2019.

160. J. Fiacco, E. Cotos, and C. Rosé, "Towards enabling feedback on rhetorical structure with neural sequence models," in Proceedings of the 9th International Conference on Learning Analytics \& Knowledge. ACM, 2019, pp. 310-319.

161. "Steam universe: Emerging technology driving education IT," https://tinyurl.com/ w8cfole, accessed: 2020-04-13.

162. J. P. Daries, J. Reich, J. Waldo, E. M. Young, J. Whittinghill, A. D. Ho, D. T. Seaton, and I. Chuang, "Privacy, anonymity, and big data in the social sciences," Communications of the ACM, vol. 57, no. 9, pp. 56-63, 2014.

163. Y. Xiao and J. Hu, "Assessment of optimal pedagogical factors for canadian esl learners' reading literacy through artificial intelligence algorithms," International Journal of English Linguistics, vol. 9, no. 4, pp. 1-14, 2019.

164. "Heartbeat," https://tinyurl.com/r63t5tr, accessed: 2019-12-18.

165. "9 amazing benefits of technology in the classroom $(+18$ best ways to incorporate technology)," https://www.jenreviews.com/classroom-technology/, accessed: 2019-1218. 
166. "Technology can hurt students' learning, research shows," https://tinyurl.com/ ybwaea86, accessed: 2020-04-13.

167. J. Liu and J. Cohen, "Measuring teaching practices at scale: A novel application of textas-data methods," Educational Evaluation and Policy Analysis, p. 01623737211009267, 2021.

168. "Carnegie Learning," https://www.carnegielearning.com/products/ software-platform/mathiau-learning-software/, accessed: 2020-04-16.

169. J. Yang and B. Zhang, "Artificial intelligence in intelligent tutoring robots: A systematic review and design guidelines," Applied Sciences, vol. 9, no. 10, p. 2078, 2019

170. P. Steinke and P. Fitch, "Minimizing bias when assessing student work." Research \& Practice in Assessment, vol. 12, pp. 87-95, 2017.

171. A. B. Arrieta, N. Díaz-Rodríguez, J. Del Ser, A. Bennetot, S. Tabik, A. Barbado, S. García, S. Gil-López, D. Molina, R. Benjamins et al., "Explainable artificial intelligence (xai): Concepts, taxonomies, opportunities and challenges toward responsible ai," Information Fusion, vol. 58, pp. 82-115, 2020.

172. "Scheduling for learning, not convenience," https://www.gettingsmart.com/2017/02/ scheduling-for-learning-not-convenience/, accessed: 22020-04-13.

173. Y. Bao, Y. Peng, C. Wu, and Z. Li, "Online job scheduling in distributed machine learning clusters," in IEEE INFOCOM 2018 - IEEE Conference on Computer Communications, April 2018, pp. 495-503.

174. M. R. Georgescu and I. A. Bogoslov, "Importance and opportunities of sentiment analysis in developing e-learning systems through social media," in DIEM: Dubrovnik International Economic Meeting, vol. 4, no. 1. Sveučilište u Dubrovniku, 2019, pp. 83-93.

175. K. Ahmad, S. Zohaib, N. Conci, and A. Al-Fuqaha, "Deriving emotions and sentiments from visual content: A disaster analysis use case," arXiv preprint arXiv:2002.03773, 2020 .

176. "Predicting employment through machine learning," https://tinyurl.com/ul3lnk8, accessed: 2020-01-20.

177. W. Holmes and S. Anastopoulou, "What do students at distance universities think about AI?" in Proceedings of the Sixth (2019) ACM Conference on Learning@ Scale. ACM, 2019, p. 45.

178. "How to address new privacy issues raised by artificial intelligence and machine learning," https://tinyurl.com/y3dya25f, accessed: 2020-01-20. 